\title{
Análisis crítico de la idea de cooperación: el caso de la empresa cooperativa*
}

\author{
José María Vaquero Sánchez \\ GSD Cooperativa - Doctor en Derecho
}

Recibido: 12-2-2015

Aceptado: 6-3-2015

Sumario: 1. Propósito 2. Presupuestos de partida 3. Análisis categorial de la cooperación 3.1 La cooperación en el ámbito de la biología: etología y evolución 3.2. La cooperación en el ámbito de las matemáticas: Teoría de juegos y economía. 4. Núcleo de la Idea de Cooperación 4.1. Exposición del núcleo de la cooperación 4.2. Reconstrucción de la Historia del Cooperativismo como movimiento empresarial: el trinomio «libertad, igualdad y fraternidad» 4.3. Líneas genéricas (ensayo) de reconstrucción de los Principios Cooperativos 5. El futuro y el papel crítico de la empresa cooperativa

Resumen: Se analiza en el presente artículo la idea de cooperación partiendo de la concepción filosófica según la cual las ideas aparecen por la confrontación de diferentes categorías inconmensurables entre sí. Se analiza el concepto de cooperación en el ámbito de la biología, la etología, la teoría de juegos y la economía para construir, a partir de ellas, la idea nuclear de cooperación. A continuación y partiendo de dicha idea nuclear se proponen las líneas genéricas de reconstrucción de la génesis y desarrollo del movimiento cooperativo así como de los principios cooperativos. Por último se determina la naturaleza de la forma empresarial cooperativa y se propone una interpretación, en base a la concepción del cooperativismo empresarial, del futuro y papel crítico de la empresa cooperativa en el siglo XXI.

Palabras clave: cooperación, biología, economía, teoría de juegos, evolución, filosofía, empresa

Abstract: Based on the philosophical conception asserting that its origin arises from the opposing views of many different categories which cannot be measured against each other, this article analyzes the idea of cooperation. Firstly, the concept of cooperation is analyzed in fields such as biology, ethology, game theory and economics in order to build the core meaning of coop-

* «Si resultara, cierto que alimentar a los extraños es inherente a la naturaleza toda, como algo que tiene carácter de ley general, muchos enigmas quedarían entonces resueltos». Goethe 
eration itself. Secondly, based on this essential definition, reconstruction of the basic lines of the genesis and development of the cooperative movement and principles is proposed. Finally, the nature of the cooperative model is defined and an interpretation of it is proposed, based on the concept of entrepreneurial cooperative organization, its future and key role in the 21st century.

Key words: cooperation, biology, economics, game theory, evolution, philosophy, business. 


\section{Propósito}

Nos proponemos en este trabajo realizar un estudio crítico de la idea de Cooperación. Nuestra pretensión general es doble. Por un lado tenemos la intención de establecer un marco general de interpretación de dicha idea así como una reconstrucción de la misma. Por otro lado y una vez delimitado el arco o radio de la idea de cooperación, interpretar el caso particular de la cooperación en el ámbito de la empresa, o más concretamente, la naturaleza de la empresa cooperativa. De este modo, nuestro trabajo tiene una naturaleza filosófica entendiendo que ésta, tal y como sucede en la tradición académica platónica, se ocupa del análisis de las ideas así como de la clasificación de las formas de la realidad. En este caso, la forma de la realidad que trataremos será, como decimos, la de la empresa cooperativa.

\section{Presupuestos de partida}

En la medida que nuestra reflexión pretende situarse en el ámbito de la investigación filosófica entendemos que tal reflexión en tanto que distinta a otro tipo de investigaciones (científicas, políticas, sociales, económicas .) aunque no por ello desconectada (filosofia perennis) de las mismas, requiere una metodología concreta que debemos explicitar dado que filosofías hay de muchos tipos en el mismo sentido que Aristóteles reconocía que las sustancia se podía decir de muchas maneras. En el caso de la filosofía también. En nuestro caso y tal como hemos explicitado antes, nuestra perspectiva se mueve en el ámbito de la filosofía de tradición académica platónica en tanto entiende que el objeto de estudio de la filosofía son las ideas. Ahora bien, las ideas aparecen, tal es nuestra concepción, a partir de la propia actividad humana determinada histórica y socialmente. Por esta razón, no forman parte de un cielo eterno (topos uranos) en el que se encuentran dispuestas a ser desveladas o aprehendidas sino que más bien brotan de la confrontación dialéctica de las diferentes praxis productivas (económicas, políticas, sociales, científicas) de la actividad humana en su conjunto' ${ }^{1}$.

1 «El saber filosófico es un saber acerca del presente y desde el presente. La filosofía es un saber de segundo grado, que presupone por tanto otros saberes previos, «de primer grado» (saberes técnicos, políticos, matemáticos, biológicos...). La filosofía, en su sentido estricto, no es «la madre de las ciencias», una madre que, una vez crecidas sus hijas, puede considerarse jubilada tras agradecerle los servicios prestados. Por el contrario, la filosofía presupone un estado de las ciencias y de las técnicas lo suficientemente 
En este sentido distinguimos dos tipos de materiales diferenciados al respecto: por un lado las categorías y por otro las ideas. Las categorías serían elementos propios de los saberes científicos y las ideas, tal y como hemos afirmado, elementos de la reflexión filosófica. El término «categoría» se utiliza en el lenguaje filosófico para aludir a un modo de catalogar, enjuiciar o criticar la realidad. Así encontraríamos numerosas conceptualizaciones de las categorías según los diferentes autores: Aristóteles con sus diez categorías (sustancia, cualidad, cantidad, relación, lugar ) referentes a cada uno de los modos en los que se manifiesta la sustancia. De este modo cada categoría se correspondería con un estudio particular de la realidad, así, por ejemplo, la «cantidad» sería estudiada por la «ciencia matemática». Cada categoría alude a una esfera de estudio de la realidad, de tal modo que las categorías se corresponderían, en general, con las diferentes ciencias particulares.

Las categorías en cuanto diferentes formas de clasificación de la realidad se podrían entender de dos formas: o bien desde su determinación lingüístico-semántica o desde la determinación material-ontológica. Las primeras se situarían en la interpretación de las categorías como una red que se extiende a un grupo de objetos. Red que puede entenderse como las partes de una oración por ejemplo. Así, las categorías serían los predicados de las «proposiciones gramaticales» u «oraciones». En este sentido las entendió el propio Aristóteles: «el trigo es abundante», donde "abundante» haría referencia a una categoría propia de la cantidad. Ocurría también que en determinados predicados o que a determinados predicados se les puede atribuir el carácter de sustancia, por ejemplo: «el lucero matutino es el lucero

maduro para que pueda comenzar a constituirse como una disciplina definida. Por ello también las Ideas de las que se ocupa la filosofía, ideas que brotan precisamente de la confrontación de los más diversos conceptos técnicos, políticos o científicos, a partir de un cierto nivel de desarrollo, son más abundantes a medida que se produce ese desarroIlo». BUENO, G.: ¿Qué es la filosofía? Ed. Pentalfa Oviedo, 1996, p. 10. "La Filosofía, como oficio, es, en suma, la institucionalización de ese trabajo con Ideas que llamamos «reflexión»—es decir, distanciamiento, reconsideración en «segundo grado»-, no sólo analizándolas, sino también componiéndolas «geométricamente», en la medida en que ello sea posible. La Filosofía académica aspira, sobre todo, a ser una "Geometría de las Ideas», para ofrecer un entramado ideal, que, por sí mismo, es ya una realidad cultural, cualquiera que sea el alcance que pueda tener en el conjunto de las realidades culturales. En tanto que las Ideas sólo pueden brotar del ser mismo social e histórico del hombre, el material filosófico procede íntegramente del estado cultural en que vive, pero siempre que no se olvide que la tradición histórica es un componente esencial de este estado cultural». BUENO, G.: El papel de la filosofía en el conjunto del saber, Ed. Ciencia Nueva, Barcelona, 1972, pp. 16-17. 
vespertino». En esta oración, a la que los analistas lógicos como Bertrand Russell le han dado tantas vueltas a lo largo del siglo xx, resultaría que el «predicado» también es sustancia o sujeto y esta sería la forma en que estarían aquellas categorías que pertenecerían a la esfera material-ontológica.

Por otro lado, hemos de decir que el concepto de categoría implica o hace referencia a la idea de clasificación. Las categorías son clasificaciones de los objetos de la realidad. Pero no toda clasificación implica una categoría puesto que la categoría conlleva un ordenamiento de las partes clasificadas. Una categoría, por tanto, no tiene un carácter universalizador. Así, las categorías surgirían cuando se produce el acotamiento de un "conjunto de términos» relacionados entre sí a través de la relación de identidad. En este sentido, cada categoría envolvería una serie de relaciones entre objetos o términos cerrada e incomunicable con otras esferas o categorías en forma de teoremas².

En cuanto a las «Ideas», la definición puede entenderse desde muchos puntos de vista (psicológicos, lógicos, ontológicos ) pero dado que esta no es una trabajo sobre la «naturaleza» del concepto y sí de análisis filosófico vamos a circunscribir la definición de esta al ámbito de la filosofía u ontología y en este sentido hemos de afirmar como primer punto de aproximación que las Ideas están en relación con las categorías en la medida en que brotan o emanan de las actividades que en estas se realizan; de tal forma que éstas no son solo y exclusivamente el resultado del pensamiento tanto en su vertiente psicológica, sociológica u otras sino que poseen una realidad pro-

2 «El teorema geométrico que establece la igualdad de los ángulos opuestos por el vértice propone una identidad esencial (igualdad interna) entre términos distintos, pero ligados sinectivamente a través de esquemas de identidad sustancial (las rectas cuya intersección determinan los ángulos), trabadas en un sistema sinalógico (son precisamente estos esquemas de identidad sustancial, intersectados en el sistema de las dos rectas que se cortan, la fuente de las relaciones internas de igualdad). BUENO, G.: Teoría del Cierre Categorial. Vol. 1, Ed. Pentalfa, Oviedo, 1992, p. 163. En general, consultar en la misma obra el apartado dedicado al concepto de «identidad sintética», pp. 160-180. «[...] porque la relación de igualdad (isología) entre la masa de inercia y la masa de gravitación es, desde luego, una relación de identidad, pero no es analítica, in independiente de la experiencia, puesto que establece la síntesis de experiencias operatorias muy distintas, y se apoya en ellas: es una identidad sintética. La identidad sintética, al darse en la intersección de diversos contextos confluyentes, implica que tales contextos estén estructurados en torno esquemas de identidad material, pide más de un esquema material de identidad capaz de confluir sintéticamente con otros». BUENO, G.: «El cierre categorial aplicado a las ciencias físico-químicas», recogido en VV.AA.: Actas del primer Congreso de Teoría y Metodología de las Ciencias, Ed. Pentalfa, Oviedo, 1982, p. 139. 
pia que no se circunscribe a ninguna categoría en concreto. Es por ello que «ldeas» y "Categorías» tienen un estatuto ontológico, tal y como veíamos antes con Aristóteles, pues ambas brotan de la actividad práctica u operatoria de las actividades humanas. Ahora bien, mientras que las "categorías», como dijimos, ordenan o sistematizan internamente un parte $u$ "esfera» de la realidad, las Ideas se refieren precisamente a aquellos términos de la realidad que transcienden el ámbito de cada categoría particular ${ }^{3}$.

En este sentido y por nuestra metodología, debemos empezar por analizar aquellos ámbitos científicos, categoriales, en los cuáles aparece tratada y forma parte del campo de los mismos el término cooperación pues, tal y como hemos dicho, la idea de cooperación ha de construirse articulando de forma totalizadora los resultados que aparecen en dichos campos. Una vez realizado este estudio genérico abordaremos en más detalle la cuestión de la aparición del cooperativismo en su sentido empresarial como objeto principal de este trabajo, pero en la medida en que está conexionada o articulada a partir de estos.

\section{Análisis categorial de la cooperación}

\subsection{La cooperación en el ámbito de la biología: etología y evolución}

En primer lugar, nos parece propio empezar por una exposición de la cooperación desde el punto de vista de la biología. Las razones de dicha decisión provienen tanto de razones externas como internas. Desde un punto de vista puramente ad hominen se viene reconociendo por parte de los diferentes estudiosos de las raíces biológicas de la evolución de las especies que las conductas cooperativas forman parte esencial de la misma y se busca su fundamentación (y también justificación) en mecanismos de carácter puramente biológicos. En este contexto se articulan las tesis de Kropotkin cuando en su obra El apoyo mutuo (1902) situada en el contexto intelectual del desarrollo del evolucionismo darwinista y la defensa de las implicaciones políticas que del mismo hiciese T. Huxley en su «Manifiesto por la lucha por la supervivencia» (1888), trata de encontrar los principios de

3 Confert. las entradas redactadas por J.M. FERNÁNDEZ CEPEDAL «Categoría»e «Idea» en QUINTANILA, M.A. (COORD): Diccionario de Filosofía Contemporánea, Ed. Sígueme, Salamanca, 1976, pp. 58-90 y 213-216. 
la cooperación en el funcionamiento o mecanismo de los fenómenos naturales ${ }^{4}$.

La tesis principal de Kropotkin frente a Huxley consiste en tratar de defender que en los mecanismos de evolución intervienen además de factores de lucha elementos de cooperación y altruismo. De tal forma que la evolución por selección natural no resulta ser, tal y como entendía Huxley, un mecanismo de lucha de todos contra todos donde el más fuerte, bajo la forma de variación que produce ventaja adaptativa y competitiva, sobreviviría. Kropotkin trata de demostrar que dicha posición además de incorrecta en términos biológicos resultaría harto peligrosa en términos morales y aún políticos (justificación de la eugenesia, maltusianismo político $)^{5}$.

4 «Whether human nature is competent, under any circumstances, to reach, or even seriously advance towards, this ideal condition, is a question which need not be discussed. It will be admitted that mankind has not yet reached this stage by a very long way, and my business is with the present. And that which I wish to point out is that, so long as the natural man increases and multiplies without restraint, so long will peace and industry not only permit, but they will necessitate, a struggle for existence as sharp as any that ever went on under the regime of war. If Istar is to reign on the one hand, she will demand her human sacrifices on the other». HUXLEY, T. "The Struggle for existence in human Society», Collected Essays, IX, 1888. Por cierto, cabe destacar que estas ideas de Huxley ya fueron duramente criticadas por el filósofo Max Scheler según el que: "la relación entre el medio natural humano y el de los demás organismos no es una relación entre un todo y sus partes. A su juicio, el medio natural del gusano o del arenque no está contenido en el medio natural del hombre, sino que se define autónomamente por la vitalidad propia de cada una esas especies. Observemos de paso que al negar que la vida de las distintas especies orgánicas se despliegue en un medio unitario, Scheler aporta un nuevo argumento para restringir el alcance del principio mecanicista de la lucha por la vida, pues lo que se está negando es precisamente que exista el terreno común en el que habría de darse esa lucha. De este modo cobra fuerza la concepción de la naturaleza orgánica como una totalidad simbiótica en la que la cooperación prima sobre la competencia». RODRÍGUEZ DUPLÁ, L.: "Las ideas biológicas de Max Scheler», $\Delta \alpha \iota \mu \omega v$. Revista Internacional de Filosofía, n. ${ }^{\circ}$ 57, 2012, 97-115, p. 112.

5 «Debido a las razones ya expuestas, cuando más tarde las relaciones entre el darwinismo y la sociología atrajeron mi atención, no pude estar de acuerdo con ninguno de los numerosos trabajos que juzgaban de un modo u otro una cuestión extremadamente importante. Todos ellos trataban de demostrar que el hombre, gracias a su inteligencia superior y a sus conocimientos puede suavizar la dureza de la lucha por la vida entre los hombres pero al mismo tiempo, todos ellos reconocían que la lucha por los medios de subsistencia de cada animal contra todos sus congéneres, y de cada hombre contra todos los hombres, es una «ley natural». Sin embargo, no podía estar de acuerdo con este punto de vista, puesto que me había convencido antes de que, reconocer la despiadada lucha interior por la existencia en los límites de cada especie, y considerar tal guerra como una condición de progreso, significaría aceptar algo que no sólo no ha sido demostrado aún, sino que de ningún modo es confirmado por la observación directa». KROPOTKIN, P., El apoyo mutuo, Ed. Madretierra, Colombia, 1989, p. 15 
En este sentido aporta Kropotkin la explicación de aquellos elementos de cooperación que se darían en las especies y que darían lugar a la supervivencia de la misma. De este modo en el capítulo primero de su obra muestra una exhaustiva recopilación a modo de ejemplos relativos a los más diversos animales que mostrarían, según Kropotkin, que la ayuda mutua es un mecanismo de evolución tan importante, cuanto menos, como la lucha. En este sentido recoge ejemplos de la vida de las hormigas, termitas, abejas, escarabajos, aves, grullas o papagayos... que cooperan para conseguir sus fines tanto alimenticios como reproductivos.

La tesis principal que articula toda la obra de Kropotkin puede resumirse en la idea según la cual la vinculación de los miembros de una especie a través del desarrollo de mecanismos de ayuda mutua se incrementan de forma notable las posibilidades de supervivencia y reproducción y por lo tanto la evolución. Dichos mecanismos también se pueden encontrar en las sociedades humanas y la idea de Kropotkin es que conservarlos y fomentarlos es sinónimo de un progreso tanto social y económico como ético y moral 6 . A nuestro juicio, y sin cuestionar al menos de forma directa la tesis de Kropotkin, hemos de afirmar que nos parece que carece de un cierto carácter dialéctico en el sentido en que no reconoce, al menos formalmente, que la cooperación que se establece entre los miembros de un determinado grupo, ya sea animal o humano, se establece en virtud de las relaciones de los mismos frente a otros.

Es decir, los mecanismos de «apoyo mutuo» se establecen en relación de competencia frente a los mecanismos de otros grupos por la supervivencia. Es cierto que las hormigas establecen relaciones de estructuración y apoyo mutuo entre ellas tal y como se conoce en los es-

6 "La tierra se identificaba con los habitantes. En lugar de las uniones anteriores por la sangre, crecieron las uniones territoriales, y esta nueva estructura evidentemente ofrecía muchas ventajas en determinadas condiciones. Reconocía la independencia de la familia y hasta aumentaba esta independencia, puesto que la comuna aldeana renunciaba a todo derecho a inmiscuirse en lo que ocurría dentro de la familia misma; daba también una libertad considerablemente mayor a la iniciativa personal; no era un principio hostil a la unión entre personas de origen distinto, y además, mantenía la cohesión necesaria en los actos y en los pensamientos de los miembros de la comunidad; $y$, finalmente, era lo bastante fuerte para oponerse a las tendencias de dominio de la minoría, compuesta de hechiceros, sacerdotes y guerreros profesionales o distinguidos que pretendían adueñarse del poder. Debido a esto, la nueva organización se convirtió en la célula primitiva de toda vida social futura; y en muchos pueblos, la comuna aldeana conservó este carácter hasta el presente». KROPOTKIN, P., op. cit., p. 76. 
tudios actuales de biología evolutiva7 ${ }^{7}$. Ahora bien, no es menos cierto que se establecen en virtud de la «lucha» frente a otras posibles formas de organización externas que están en competencia con estas. El propio Kropotkin lo menciona en algún momento en su obra aunque a nuestro parecer de forma tangencial u oblicua pues de alguna forma no llega a dar a dicha posición la relevancia que a nuestro juicio posee $^{8}$. La importancia, a nuestro juicio, de esta consideración dialéctica la tendremos en cuenta más adelante cuando construyamos a partir de estos resultados lo que vamos a denominar núcleo de la Idea de cooperación en la medida que dicho núcleo lo vamos a construir en relación a los resultados que obtendremos del análisis de las diferentes manifestaciones categoriales del mismo.

En este sentido y siguiendo las investigaciones en biología evolutiva más recientes, el descubrimiento de los llamados «animales eusociales» nos ha puesto en la pista tanto de las ventajas adaptativas del altruismo o la cooperación pero en la medida que dichas ventajas también suponen beneficios para el propio individuo de forma particular. También, se han estudiado las ventajas de la cooperación a nivel incluso fenotípico, incluso más allá de la relación de parentesco, en términos de modelos altruistas a nivel microbiológico y son estas investigaciones las que podemos utilizar para afirmar la incompletitud de la tesis de Kropotkin en favor de una perspectiva dialéctica en la medida en que

7 «La organización del mundo vivo es jerárquica. Cada forma de vida, desde las bacterias más simples hasta los organismos eucariotas multicelulares complejos, cuyas funciones están codificadas por miles de genes y que viven en grandes grupos sociales, está constituida por unidades de un nivel inferior que se agrupan y cooperan para formar niveles organizativos superiores (genes, cromosomas, bacterias, células eucariotas, organismos multicelulares y sociedades). Los momentos más importantes en la diversificación de la vida han supuesto transiciones entre estos niveles de organización impulsas por la cooperación entre entidades biológicas de cada nivel jerárquico. El resultado es que cada nivel está formado por miembros que en su estado individual habrían competido con ferocidad, pero que en su forma presente muestran comportamientos de cooperación enormemente complejos y altruistas». NAVARRO, A., Contra natura. La esencia conflictiva del mundo vivo. Servicio de Publicaciones de la Universidad de Valencia, 2009, p. 37.

8 Cuando menciona la «prudencia» de la grulla que la libra de sus enemigos, las estrategias de los papagayos frente al colono australiano o cuando reconoce en sus propósitos al escribir la obra que: "Era necesario demostrar que las costumbres de apoyo mutuo dan a los animales mejor protección contra sus enemigos, que hacen menos difícil obtener alimentos (provisiones invernales, migraciones, alimentación bajo la vigilancia de centinelas, etc.), que aumentan la prolongación de la vida y debido a esto facilitan el desarroIlo de las facultades intelectuales; que dieron a los hombres, aparte de las ventajas citadas, comunes con las de los animales, la posibilidad de formar aquellas instituciones que ayudaron a la humanidad a sobrevivir en la lucha dura con la naturaleza y a perfeccionarse, a pesar de todas las vicisitudes de la historia». KROPOTKIN, P., op. cit., p. 19. 
las actitudes altruistas o cooperativas revierten en un beneficio para la mejora de la supervivencia del individuo frente a amenazas externas e incluso para entender los beneficios, tal y como señala Kropotkin, para el propio individuo cooperador frente a otros que no lo sean ${ }^{9}$.

Es cierto que en este caso son numerosos los ejemplos de cooperación en el ámbito de los animales. La caza cooperativa, por ejemplo, sería un modelo muy claro de dicho comportamiento. Los etólogos han demostrado que las estrategias cooperativas en cuanto a la búsqueda de alimento son más productivas, beneficiosas y reducen el peligro de fracaso en un grado muy alto. Las estrategias de los primates han sido muy estudiadas en el ámbito de la etología ${ }^{10}$ mostrando de forma evidente su relevancia como mecanismos de adaptación evolutivo e incluso en el proceso de hominización: «los antropólogos y los sociólogos han opinado que el proceso de hominización se ha gestado, en gran parte, en el complejo conductual-cooperativo que la caza impone y que este ha situado lentamente al hombre y a sus ancestros en una posición única dentro del mundo animal (...) la cacería cooperativa, la distribución de alimento y la división sexual del trabajo en este contexto configuran uno de los elementos constitutivos del modelo hominoideo» ${ }^{11}$.

9 «It is possible that advocates of particular theories about the evolution of altruism will see our model as fitting squarely into their framework. What we have tried to emphasize is that there is a basic and very general requirement that underlies all these theories: an increase in the frequency of an altruistic genotype requires that carriers of the genotype are overcompensated for their altruistic sacrifice by benefits received from others. Not all carriers must help or be helped, but on average, carriers must end up with higher direct fitness benefits tan carriers of alternative genotypes. This is a basic principle of natural selection and true, regardless of whether one prefers to think in terms of kin selection, multi level selection, reciprocal altruism or other frameworks». FLETCHER, J.A. \& DOEBELI, M.: «A simple and general explanation of altruism», Proc. R. Soc. B. 276, 2009, PP. 13-19, p. 18.

10 Confert. «Evaluation des expériences portant sur la coopération en fonction de la définition proposée par Boesch et Boesch (1989) pour les chimpanzés chasseurs, et de notre définition comprennant 3 critères: but commun, communication et réciprocité». CHALMEAU R. \& GALLO A. "La coopération chez les primates», L'année psychologique. vol. 95, 1995, n. ${ }^{\circ 1}$. pp. 119-130, p. 125.

11 SABATER PI, J., El chimpancé y los orígenes de la cultura, Ed. Anthropos, Barcelona, 1984, p. 101-102. "...los referidos primates [chimpancés de la estepa de Tanzania] inician la cacería después de una opípara comida vegetal y nunca durante un periodo de excitación que podría haber sido provocado por interacciones intragrupales. El periodo de persecución de la presa suele ser muy laborioso y siempre se desarrolla en completo silencio: cuando se trata de lograr un animal que vive en manadas se intenta, primero, su separación del grupo; los cazadores se mantienen dentro de una gran área al objeto de evitar cualquier evasión y actúan siempre dentro de un contexto cooperativo que podría ser considerado como un eslabón intermedio entre la cacería cooperativa de los felinos o los cánidos y la caza compleja de los humanos». Ibídem, p. 99. 
En conclusión creemos estar en disposición de afirmar que la cooperación, en el sentido que estamos manifestando, es un mecanismo biológico de carácter general evolutivo-adaptativo que se manifiesta en el desarrollo de las especies así como en la dialéctica de unas con otras y que está en la raíz de los mecanismos de la vida y la evolución de la misma. Los organismos han tenido la necesidad de desarrollar estrategias de cooperación para adaptarse al medio en su dialéctica con el resto de los organismos ${ }^{12}$. Por esta razón entendemos que la idea cooperación tiene una raíz biológico-evolutiva como mecanismo de supervivencia de las especies e incluso como mecanismo propio de los homínidos, tal como apunta la tesis de Sabater Pi, en el desarrollo de su vida social incluyendo a los propios seres humanos. ${ }^{13}$

12 «Dentro de cada una de las estructuras que contienen ADN hay centenares o miles de genes agrupados en uno o varios cromosomas. Estos conjuntos de genes son un prodigio de cooperación entre entidades que competían encarnizadamente en épocas pretéritas: bacterias que habian sido independientes y que ahora forman orgánulos imprescindibles; o genes que forman cromosomas y genomas, pero que probablemente descienden de unidades catalizadoras individuales pobladoras de una sopa primordial. ¿Implica toda esta cooperación una situación estable de armonía completa? Una vez más, la respuesta es no». NAVARRO, A., Contra Natura, op. cit., p. 85.

${ }^{13}$ Nos parece interesante, al menos citar aunque no podamos desarrollar, las implicaciones que ya no tanto para la propia evolución biológica tiene la cooperación, cuanto para el origen y desarrollo del propio conocimiento humano apuntadas por J.B. Fuentes Ortega en el sentido en que viene a considerar que la cooperación más que una estrategia sería la necesidad que un organismo en su búsqueda de alimentación de encontrarse con otros y operar conjuntamente con ellos, es decir, cooperar: «la estructura topológica tri-posicional que adquiere la vida social cuando ocurre que para cualesquiera dos individuos operatorios cuyos cuerpos y operaciones sean mutuamente perceptibles, sea preciso sin embargo contar, y como condición interna necesaria de la prosecución de sus interrelaciones operatorias (en principio, de sus co-operaciones), con las operaciones de algún otro tercer individuo operatorio cuyo cuerpo y operaciones no puedan estar, de entrada por razones geográfico-físicas, presentes en el espacio perceptivo y operatorio de los dos primeros». FUENTES ORTEGA, J.B. "La teoría del origen trófico del conocimiento de Ramón Turró: Un ensayo sobre su trasfondo histórico-filosófico y sus posibilidades de desarrollo teórico en el sentido de una concepción (neo) aristotélica de la vida». Rev. Psychologia Latina, Vol. 1, 2010, pp. 27-69, p. 66. Incluso nos parece que sería muy interesante analizar en este contexto las ideas de aquellos biólogos (nuevos biólogos que propugnan una nueva biología) para los que la cooperación juega un papel esencial en la evolución: "Las mismas plantas que aparentemente compiten sobre la superficie, cooperan bajo el suelo y se fusionan en una entidad reticular que es imprescindible para su funcionamiento. Incluso al nivel de los ciclos geoquímicos, aparecen interacciones complejas en las que intervienen agentes biológicos, como son los virus en la formación de las nubes o las bacterias en la nucleación de la nieve». HEREDIA DOVAL, D.: Redes, sistemas y evolución: hacia una nueva biología (Tesis Doctoral), Dep. de Biología Evolutiva y Biodiversidad, Facultad de Ciencias, Universidad Autónoma de Madrid, 2013, p. 107 
3.2. La cooperación en el ámbito de las matemáticas: Teoría de juegos y economía

Encontramos igualmente el desarrollo de estrategias de carácter cooperativo (y no cooperativo), altruismo o egoísmo en el ámbito de la resolución de problemas. El nacimiento de la teoría de juegos y su pionero son discutibles y no hay un acuerdo en la comunidad científica sobre quién y en qué circunstancias se originó inicialmente la misma. Ahora bien, lo que sí parece claro es la naturaleza causal que lleva a determinados individuos a estudiar la racionalidad de la toma de decisiones. Seguramente Von Neumann no imagina cuando jugaba al póker e intentaba pensar por sus rivales que el alcance de su pensamiento albergaba límites insospechados. La cuestión que aquí nos interesa resaltar es determinar cuál es el alcance de beneficio o perjuicio que la estrategia de la cooperación tiene frente a otro tipo de estrategias ${ }^{14}$.

La situación tipo que resumiría dicha cuestión es aquella en la que se desarrolla un juego donde en cada ronda los participantes están obligados a desarrollar una estrategia y necesariamente interactuar con sus rivales. Así, se establece una matriz de recompensa que determina el ámbito lógico de posibilidades de interacción de los jugadores. En los juegos de decisión cooperativa, tipo el del cazador y el ciervo ${ }^{15}$, resulta que la «apuesta» por la decisión que toma partido por la estrategia de cooperación mutua por parte de ambos cazadores es la mejor opción en cuanto a beneficio mutuo tanto individual como grupalmente ${ }^{16}$.

14 «Hablando en términos generales e intuitivos, podríamos decir que la Teoría de Juegos estudia situaciones de conflicto y cooperación a las que denominamos juegos, en las que interactúan individuos racionales, analizando los comportamientos y resultados que son de esperar, bien mediante decisiones individuales (caso de los juegos no cooperativos), bien mediante acuerdos entre los participantes (caso de los juegos cooperativos)». PÉREZ NAVARRO, J., Teoría de juegos (Prólogo), Ed. Pearson Educación, Madrid, 2004, p. 9.

15 Ibídem, pp. 66 y ss.

16 Resultan especialmente interesantes en este sentido las conclusiones en cuanto a la influencia de la cooperación en el desarrollo y origen de la sociedad humana a las que llega Ignacio Gómez Portillo en su Tesis doctoral "La evolución de la cooperación y el origen de la sociedad humana», Dep. de Físicas, Grupo de Física Estadística, de la Universidad Autónoma de Barcelona, año 2013: "Resulta importante notar que los sistemas cooperativos no surgen espontáneamente desarrollados sino que se forman mediante un proceso en el que la población de partes orgánicas del sistema crece en el tiempo hasta que la misma alcanza la edad adulta, caracterizada por un número de individuos aproximadamente constante. A lo largo de este proceso la población del sistema se encuentra por debajo de individuos que puede contener el medio, de manera que la tragedia de los comunes no es posible $y$, por tanto, bajo condiciones 
De este modo parece al menos que en términos de beneficio no a corto sino a largo plazo las estrategias cooperativas son más beneficiosas, en general, que las estrategias individualistas que, pueden ser muy beneficiosas a corto plazo, pero resultan perjudiciales para los intereses del individuo en el largo plazo. En este sentido se han estudiado también las tendencias «naturales» a la cooperación por parte de individuos humanos en relación con sus semejantes y con sus no-semejantes (cooperación por parentesco o no parentesco ).

Ahora bien, hemos de matizar a partir de esta idea general un error, que a nuestro juicio, es muy común en los teóricos del cooperativismo pues se suele entender que la apuesta por la estrategia individual se mueve por principios puramente egoístas como si el egoísmo fuese fruto de una maldad irracional de algunos seres humanos. Nada más lejos de la realidad pues desde el punto de vista de la racionalidad de la conducta la acción egoísta es tan racional como la no-egoísta y en términos evolutivos, en el sentido que hemos determinado antes, ambas son igualmente racionales ${ }^{17}$. La diferencia, a nuestro juicio y los veremos más profundamente más adelante, reside en los principios que determinan la acción y no en la acción misma. En cuanto acciones ambas son racionales en la media que ambas se determinan a partir de un cálculo reflexivo. La diferencia reside en los principios y valores, entendidos estos bajo una concepción de la realidad (filosofía), que determinan la acción.

Hemos de considerar, igualmente, como relevante para nuestro estudio, aunque la teoría de juegos es una rama de la ciencia matemática bastante desarrollada, las tesis del matemático John Nash y su contribución a la teoría de juegos y en concreto a la de los juegos cooperativos. Nash parte de la idea de sujetos egoístas y entiende que su egoísmo a la hora de obtener beneficio es el que determina la elección de estrategias cooperativas, de tal forma que el compromiso adquirido por dos o más jugadores implica un equilibro (equilibrio de Nash) en cuanto a

donde la cooperación ha mostrado poder evolucionar. De esta manera, consideramos de importancia para la correcta comprensión de la naturaleza de la vida romper con la concepción tradicional donde las poblaciones solo evolucionan saturando el medio, ampliando la teoría de la evolución por selección natural a poblaciones que se desarrollan en medios abundantes de recursos, donde la lucha por la supervivencia no es condición necesaria», p. 129.

17 «Cualquiera que sean las diferencias entre las varias escuelas económicas, toda parecen coincidir en reconocer que tanto el sujeto económico, como también la empresa, actúan racionalmente cuando tratan de asegurarse ganancias máximas». MORGENSTERN, O., "La teoría de los juegos y del comportamiento económico», American Economic Review, Yale University, Tomo XXXVIII, 1948, p. 346. 
la repartición de beneficios que se desarrollan en el juego, siempre y cuando los jugadores, claro está, no rompan el acuerdo ${ }^{18}$.

En definitiva, nos parece que un estudio crítico de la idea de cooperación pasa por no obviar sino más bien asumir los resultados que se desprenden de las conclusiones a las que, en un entorno científico, y por tanto a-valorativo en el sentido de Max Weber, se llega desde la teoría matemática en su rama de teoría de juegos tal y como realizaremos en la parte tanto de construcción del núcleo de la Idea de cooperación como en la parte final del presente trabajo.

Siguiendo con la estela de teoría matemática de juegos, empezaron a desarrollarse aplicaciones de dicha teoría en las más variadas ramas del saber y en concreto fueron muy importantes los análisis en el ámbito de la economía. La teoría de Oskar Morgenstern es, en cuanto pionera, la que hemos de considerar pues el autor escribió, precisamente junto a Von Neumann, la obra Theory of games and economic behavior. En ella se plantea la posibilidad de aplicación de la teoría de juegos al ámbito de la toma de decisiones en situaciones no estrictamente matemáticas sino de la vida real. En este sentido, el propio Morgenstern reconoce la preocupación que antes de él había tenido Leibniz por estas cuestiones con la intención de destacar la importancia de las mismas. Por esta razón se propone estudiar cuál o cuáles son las conductas racionales de los individuos y entiende a la teoría de juegos como elemento o herramienta fundamental que ayudaría a explicar e incluso prever dichas conductas con la finalidad de sistematizar el comportamiento humano en la negociación ${ }^{19}$.

El interés no puede ser más evidente pues en la medida que se puedan sistematizar la o las conductas económicas en los negocios mayor capacidad de articulación de los movimientos o estrategias para alcanzar la finalidad empresarial de aumentar la posibilidad de obtener beneficio en las mismas. De este modo, se podrá articular tanto una política competitiva con los agentes económicos que operan en un mercado similar (competidores) así como establecer las alianzas con terceros con finalidades empresariales comunes para afrontar la competencia frente a una empresa más fuerte en mejores condiciones. En

18 Confert. MONSALVE, S. El programa Nash: ¿es mejor cooperación que competencia? en «John Nash y la teoría de juegos», Lecturas matemáticas, Vol. 24, 2003, pp. 137-149. p. 145.

19 «La semejanza entre los juegos y la economía es convincente. La actitud es definitiva si se trata de problemas económicas que hasta ahora no han recibido una solución satisfactoria, o la solución de los cuales aún no ha sido planteada, y que pueden ser explicados con la ayuda de la teoría de juegos». MORGENSTERN, O., op. cit., p. 350. 
este sentido es evidente que, tal y como reconoce Morgenstern la cooperación en forma de alianzas se da más fácilmente cuando se comparten objetivos comunes ${ }^{20}$.

Pero las alianzas o cooperación por objetivos comunes hemos de entenderla sin olvidarnos de las cuestiones biológicas o conductuales analizadas en el punto anterior en el sentido de la crítica que hemos realizado a la tesis de Kropotkin y su falta de carácter dialéctico. Es decir, y en el contexto económico que estamos analizando ahora, la cooperación o alianzas se dan siempre frente a terceros competidores pues el escenario económico no es un campo de juego pacífico sino de intereses enfrentados de unas corporaciones frente a otras. En este sentido también el propio Morgenstern reconoce que es así pues entiende que en el «juego económico» intervienen y condicionan los comportamientos de los agentes el conjunto en el que el agente opera e incluso que el resultado final de la acción no está solo relacionado con el agente que la produce sino con el conjunto entero de individuos que participan el juego: «el resultado del juego no depende del comportamiento de un solo jugador, sino de la totalidad de ellos y cada uno no domina sino una parte de las variables que en su totalidad determinan el conjunto» ${ }^{21}$.

\section{Nucleo de la idea de cooperación y desarrollo histórico}

\subsection{Exposición del núcleo de la idea de cooperación}

Los resultados del análisis categorial de la cooperación desprenden, a nuestro juicio, la siguiente conclusión genérica. La cooperación es una estrategia de ayuda mutua frente a terceros para lograr un beneficio común y a la vez para el individuo-particular que por separado es imposible conseguir. Esta afirmación genérica se desprende tanto de los aspectos biológico-evolutivos de la misma como de los aspectos

20 "As soon as there is a possibility of choosing with whom to establish parallel interests, this becomes a case of choosing an ally. When alliances are formed, it is to be expected that some kind of a mutual understanding between the two players involved will be necessary. One can also state it this way: A parallelism of interests makes a cooperation desirable, and therefore will probably lead to an agreement between the players involved. An opposition of interests, on the other hand, requires presumably no more than that a player who has elected this alternative act independently in his own interest». MORGENSTERN, O. \& NEUMANN, J., Theory of games an economic behavior, Princeton University Press, Princeton, 1953, p. 221.

21 MORGENSTERN, O., "La teoría de los juegos y del comportamiento económico», op. cit., p. 350 
que la teoría de juegos y la tesis económicas de Neumann-Morgenstern hemos analizado. En este sentido podríamos definir la cooperación como la acción conjunta de varios agentes que, por una finalidad común y a la vez distributivamente particular, determinan articular frente a otros posibles agentes en competencia. Esta definición esencial recoge tanto los aspectos de beneficio de la propia cooperación en el ámbito evolutivobiológico, cuya raíz consideramos esencial a la cooperación, como de la teoría de juegos y la economía. Ahora bien, nos parece que a esta definición hemos de añadirle un elemento más.

Hemos de señalar que las estrategias cooperativas surgen como respuesta a una determinada situación. En el caso de los animales las estrategias cooperativas surgen ante el peligro de desaparición/extinción frente a otras especies. Las estrategias cooperativas son más bien, en este sentido, el resultado de una acción en forma de respuesta que de una iniciativa sin causa aparente. Dicho en términos de la lógica tradicional la estrategia cooperativa surge como consecuencia ante un determinado acontecimiento más que como causa primera. En este sentido, y obviando los problemas antropológicos que tiene, entendemos que las estrategias cooperativas tienen un sentido próximo a la idea del origen del contrato social propuesta por Rousseau. Para este, el origen de la sociedad no se produce de una forma natural (pues lo natural es el estado salvaje en libertad) sino más bien determinado por evitar o combatir el peligro que supone para la supervivencia del individuo no vivir asociado con otros (en nuestros términos, cooperando con otros) frente a la amenaza de terceros ${ }^{22}$.

Por lo tanto la idea de cooperación que surge a partir del análisis de esta como concepto desarrollado en diferentes categorías tiene, salva veritate, un carácter genuinamente dialéctico en el sentido en que su desarrollo no se de forma independiente tanto del contexto en el que se produce como de la lucha frente a otras posibles opciones. La estrate-

22 «Supongo a los hombres llegados al punto en que los obstáculos que impiden su conservación en el estado natural superan las fuerzas que cada individuo puede emplear para mantenerse en él. Entonces este estado primitivo no puede subsistir, y el género humano perecería si no cambiaba su manera de ser.

Ahora bien, como los hombres no pueden engendrar nuevas fuerzas, sino solamente unir y dirigir las que existen, no tienen otro medio de conservación que el de formar por agregación una suma de fuerzas capaz de sobrepujar la resistencia, de ponerlas en juego con un solo fin y de hacerlas obrar unidas y de conformidad. Esta suma de fuerzas no puede nacer sino del concurso de muchos; pero, constituyendo la fuerza y la libertad de cada hombre los principales instrumentos para su conservación, ¿cómo podría comprometerlos sin perjudicarse y sin descuidar las obligaciones que tiene para consigo mismo?». ROUSSEAU, J.J., El contrato social, UNAM, México, 1984, p. 20. 
gia cooperativa, por lo tanto, es construida a la vez que se destruyen, de forma dialéctica, otras formas posibles formas de estrategia para conseguir una finalidad ${ }^{23}$. Esta cuestión dialéctica la consideramos de la mayor importancia pues así vamos a entender el nacimiento formal del cooperativismo como forma de empresa específica frente a otros modelos.

De tal forma que al concepto de cooperación definido anteriormente hemos de añadirle la figura de ser un concepto genuinamente dialéctico en la medida que está construido como respuesta o como consecuencia de un estado de cosas determinado. Es dialéctico en la medida que surge como resolución, o estrategia con una finalidad, a una contradicción presente en el estado de la realidad biológica, evolutiva, matemática o pedagógica ${ }^{24}$.

Con respecto a esta última hemos de señalar que podría interpretarse la estrategia del aprendizaje cooperativo ya no solo como una estrategia frente a otras del proceso de enseñanza-aprendizaje tradicional

23 «La contradicción, que destaca en la oposición, es sólo el desarrollo de la nada, contenida en la identidad, y que se presentó en la expresión que afirmaba que el principio de identidad no dice nada (...) es una de las Ideas preconcebidas fundamentales de la lógica aceptada hasta ahora y de la representación habitual el creer que la contradicción no es una determinación tan esencial e inmanente como la identidad; más bien, cuando se tuviera que hablar de un orden jerárquico, y cuando ambas determinaciones tuvieran que ser mantenidas como separadas, entonces la contradicción tendría que ser considerada como lo más profundo y lo más esencial. En efecto, frente a ella, la identidad es sólo la determinación de lo simple inmediato, del ser muerto; en cambio, la contradicción es la raíz de todo movimiento y vitalidad; pues sólo al contener una contradicción en sí, una cosa se mueve, tiene impulso y actividad». HEGEL, G.W.F., Ciencia de la lógica, Tomo II, Ed. Solar/Hachette, Buenos Aires, 1968, p.386. Confert. BUENO, G., «Sobre la idea de dialéctica y sus figuras», El Basilisco, n. 19, Oviedo, 1995.

24 En el ámbito de la teoría pedagógica donde se desarrolla el aprendizaje bajo patrones cooperativos también podría ser considerado, en un estudio más profundo, la estrategia del aprendizaje cooperativo reconstruido según la metodología de investigación aplicada en este trabajo. El aprendizaje cooperativo sería una estrategia de aprendizaje frente a la, o como respuesta a, la metodología tradicional de la enseñanza. La teoría del aprendizaje cooperativo partiría de la idea o concepto frente al modo tradicional de que la el proceso enseñanza-aprendizaje debe tener una estructura social y socializadora frente a la tradicional individual e individualista: «Una estructura de aprendizaje cooperativa —en relación a otra individualista o competitiva - está determinada sobre todo por los cambios que se dan dentro de su estructura de la recompensa, cuyo aspecto más importante es la estructura de recompensa interpersonal (o interindividual), que se refiere a las consecuencias que para un alumno individual tiene el comportamiento o el rendimiento de sus compañeros. Esta estructura de recompensa interpersonal, pues, es distinta en función que la estructura general de aprendizaje en el aula sea cooperativa, competitiva o individualista». LINARES GARRIGA, J.E. «El aprendizaje cooperativo: aprender a cooperar, cooperando», recogido en GÓMEZ PORTILLO, A. (coord.), Habilidades sociales para la mejora de la convivencia en los centros, Ed. Consejería de Educación y Cultura, Murcia, 2006, p. 4. 
cuanto analizarla a partir de la influencia que en ella tiene, a nuestro juicio, el proceso de enseñanza-aprendizaje construido por la epistemología genética de Piaget en la medida que esta proviene de principios biológico-evolutivos. En este sentido la estrategia del aprendizaje cooperativo estaría al igual que las perspectivas matemáticas, biológicas, económicas de la cooperación enraizada en los elementos biológico-etológicos de la cooperación tal y como hemos tratado de analizar en este trabajo: "la cooperación en sentido estricto consiste en una realización en común de las operaciones de cada uno» 25 .

En definitiva, y siendo conscientes del ámbito de discusión general que hay en torno a la definición de la Idea de cooperación y la aplicación de esta a las entidades cooperativas ${ }^{26}$ afirmamos que la idea o concepto de cooperación es un término dialéctico en la media que surge de contradicciones y se determina en función de las operaciones conjuntas que llevan a cabo varios individuos (animales o humanos) para conseguir una finalidad que determine un bien común (beneficio mutuo de carácter distributivo), que individualmente no pueden alcanzar, frente a la competencia de terceros.

\subsection{Reconstrucción de la Historia del Cooperativismo como movimiento empresarial: el trinomio «libertad, igualdad y fraternidad»}

Desde esta perspectiva que estamos delineando vamos a entender la historia del movimiento cooperativo así como los principios coopera-

25 PIAGET, J., Psicología y pedagogía, Ed. Ariel, Barcelona, 1969, p. 74. Para analizar la relación directa entre biología, evolución y aprendizaje, Piaget ensaya la tesis de que el motor de la evolución es el comportamiento del individuo ante la presión del medio exterior hostil reivindicando una suerte de aprendizaje motivado por la necesidad de adaptación a dicho medio: "[] de una manera general los progresos del comportamiento se ponen de manifiesto por el aumento de los movimientos posibles del animal y sus desplazamientos en el medio lo que produce una serie de perfeccionamientos neurológicos y morfológicos». PIAGET, J.: El comportamiento motor de la evolución, Ed. Nueva Visión, Buenos Aires, 1986, p. 116.

26 «La cooperación se muestra pues en principio como una simple coadyuvancia o colaboración y la actividad cooperativa es por si misma inoperante. Más adelante, al originarse los fenómenos que acabamos de relatar, se empieza a manejar la voz cooperación en un sentido económico y social, pero no deja de emplearse en enorme variedad de acepciones, ya que la cooperación no es otra cosa en esencia sino una acción conjunto y un resultado del insoslayable carácter social del ser humano [ ] la mayor dificultad para establecer un concepto de lo que es la cooperación y qué son las cooperativas estriba en que todavía no hay en este punto un acuerdo completo en el terreno doctrinal y científico». REVENTÓS, J.: El movimiento cooperativo en España, Ed. Ariel, Barcelona, 1960, p. 20. 
tivos que han surgido a propósito de la misma. En un sentido laxo podríamos afirmar que la historia del movimiento cooperativo empezaría en los inicios prácticamente de la humanidad pues en la medida que tuvieron que establecerse como necesarias estas estrategias frente a terceros, siempre ha existido la cooperación. Es cierto que eso es así, pero dicha perspectiva nos alejaría del objetivo que nos proponemos estudiar en este artículo que es el caso de la empresa cooperativa. Es cierto que algunos tratadistas reconocen dicha cooperación in illo tempore pero a nuestro juicio no tiene un carácter crítico $^{27}$.

Así como la Historia de la Química no empieza en la época de los metales sino cuando aparece la estructuración sistemática de los elementos con Lavoisier y posteriormente con Mendeléyev, la Historia del cooperativismo en su vertiente empresarial no empieza en las sociedades funerarias de los antiguos griegos o romanos ni en las organizaciones precolombinas para el cultivo de la tierra, sin perjuicio de la influencia innegable que estas organizaciones y sus principios constitutivos hayan tenido la configuración del cooperativismo en su dimensión empresarial. En este sentido nos parece, frente a otras interpretaciones, correcta la interpretación de Paul Lambert para el que a pesar de que existan nexos innegables entre dichas organizaciones a lo largo de la historia, el cooperativismo empresarial nace formalmente en el siglo $\mathrm{XIX}^{28}$.

27 «Las organizaciones para la explotación de la tierra en común de los babilonios (Hans Muller), las sociedades funerarias y de seguros entre los griegos y los romanos, los ágapes de los primeros cristianos como forma primitiva de las cooperativas (Lujo Brentano), la vida agraria entre los germanos, las organizaciones para el cultivo de la tierra y el trabajo en las organizaciones precolombinas principalmente entre los incas y los aztecas, las reducciones de los jesuitas en el Paraguay o las cajas de comunidad en la época de la colonización española en América». ATIENZA, F.J. \& SÁNCHEZ COCA, B., "Alcázar de San Juan: cooperativismo 1900-1950», Patronato Municipal de Cultura, Alcázar de San Juan, 2005, pp. 1-2. Confert. QUIJANO, J.E., Historia y doctrina de la cooperación, Ed. Universidad Cooperativa de Colombia, Bogotá, 2004. En concreto el Capítulo 2. «Organizaciones solidarias en las sociedades precapitalistas», pp. 31-41.

28 Confert. LAMBERT, P., La doctrina cooperativa, Ed. Intercoop, Buenos Aires, 1970, p. 37 y ss. Esta misma cuestión es planteada y reconocida como confusa por Josep Reventós cuando se pregunta si existió la cooperación en los gremios y cofradías en la España medieval reconociendo no tanto la forma empresarial cooperativa cuanto un «espíritu cooperativo»: "¿Existió la cooperación en los gremios y cofradías españolas? Surge la primera dificultad al tener que considerar ambas instituciones como un todo homogéneo, cuando en realidad, se trata de asociaciones que perduran a lo largo de los siglos de la historia peninsular con diferentes características, tanto si se las compara entre sí, como si se estudia cada una de ellas en relación con los sucesivos estadios de su evolución histórica [...] puede afirmarse que, tanto en las cofradías y gremios medievales como en las mismas instituciones durante la Edad Moderna, existió un espíritu cooperativo». REVENTÓS, J.: El movimiento cooperativo en España, op. cit., pp. 34-35. 
A nuestro juicio por tanto, el cooperativismo en su sentido formalempresarial tiene un origen eminentemente industrial dado que su aparición está determinada como respuesta a una situación que formalmente solo se ha podido producir en el ámbito de la sociedad industrial. Y más concretamente en la situación de contradicción extrema entre el trabajo y el capital que se produce precisamente en la sociedad capitalista industrial decimonónica ${ }^{29}$. Es cierto que el inicio del sistema capitalista tiene sus inicios en el Renacimiento y que se consolida definitivamente en la sociedad industrial del siglo XIX. Ahora bien por qué surge el movimiento cooperativo en el siglo XIX y no anteriormente. A nuestro juicio, y entendiendo que las ideas son un producto histórico tal y como hemos presupuesto en los principios de partida, es determinante el papel ideológico que en la formación de la sociedad industrial tienen los principios de la Revolución Francesa: «libertad, igualdad y fraternidad».

Desde nuestro punto de vista el principio de la «libertad» es determinante como conformador de la conducta del individuo y su capacidad asociativa o más concretamente en cuanto a capacidad empresarial o «libertad empresarial» establecida por la ley Le Chapelier de 14 de Junio de $1791^{30}$. Esta idea de «libertad» en sentido ideológico impregna

29 «Todos estos cambios llevaron sin embargo a la ruina absoluta a la nueva clase trabajadora, la proletaria, provocando una desorganización social desconocida hasta entonces. A una situación de terrible miseria en donde los salarios eran muy bajos, el trabajo de mujeres y menores generalizado, las jornadas de trabajo interminables y a la escasa seguridad e higiene, se le une una progresiva degradación moral y psicológica del proletariado. El notable aumento de la riqueza nacional se hacía en base a la reducción del bienestar de una gran parte de la población, la cual subsistía en las peores condiciones posibles. Es únicamente en este contexto cuando nace el cooperativismo tal y como lo conceptuamos hoy en día. Son los propios agentes sociales los que se verán en la obligación de organizarse para así afrontar las necesidades que el capitalismo había desatendido. La reacción del proletariado ante la generalización del capitalismo en los paises en los que se extendía la revolución industrial provocó la búsqueda de soluciones que se concretarían, entre otras, en las sociedades cooperativas21. Incluso, en algún caso, se ha querido ampliar esa reacción frente al capitalismo a los pequeños productores, los cuales como medio de defensa también buscarían la solución en fenómenos asociativos». MERINO HERNÁNDEZ, M.: "Los orígenes del cooperativismo moderno y el socialismo premarxista», GEZKI Revista vasca de Economía Social, N. ${ }^{\circ}$ 1, 2005, 169-188, p. 175

30 En su art. 1. ${ }^{\circ}$ dice que: "Siendo una de las bases fundamentales de la Constitución francesa la desaparición de todas las corporaciones de ciudadanos de un mismo estado y profesión, queda prohibido establecerlas de hecho, bajo cualquier pretexto o forma que sea», prohíbe toda forma de asociación gremial como forma de negación del Antiguo Régimen en cuanto a su tendencia corporativa y estamentaria para afirmar la libertad de todo ciudadano de constituir una empresa: "Respecto a las sociedades definidas como «tradicionales» a mediados del siglo XIX, el capitalismo propugna la liberación 
el desarrollo del capitalismo industrial, determina el gran progreso científico-tecnológico que se produce en el siglo XIX y también, como muy observan tanto los socialistas utópicos como Marx, genera unas condiciones de trabajo y de vida verdaderamente infrahumanas para una gran parte de la población pues también instaura el modelo económico liberal-capitalista ${ }^{31}$.

Es en este contexto donde brotan las condiciones objetivas para una nueva forma de agrupación empresarial que trataría de superar esa contradicción inherente a la sociedad capitalista industrial que basada precisamente en la libertad que dicha sociedad tiene ideológicamente asumida, permite desarrollar. Esta contradicción, como es bien sabido, se formula en términos clásicos como la contradicción inherente a toda sociedad capitalista entre el trabajo y el capital en la medida en que esta se sustenta en la propiedad privada de los medios de producción.

Así lo han reconocido en sus teorías del valor-trabajo David Ricardo, Richard Owen, Saint Simon, Fourier y el propio Marx, y por esta razón, ellos son considerados los principales ideólogos de la solución y la propuesta de una iniciativa empresarial fundamentada en los valores de la igualdad, precisamente negados por la propiedad privada de los medios de producción, y reparto equitativo de la riqueza ${ }^{32}$. Y es en este contexto industrial donde aparece la empresa cooperativa, justamente como solución a este nivel de contradicciones existente en dicha sociedad. Razón según la cual y tal como hemos establecido anteriormente en términos de la lógica tradicional, la estrategia de la empresa cooperativa es más bien una consecuencia en forma de respuesta a una situación de contradicción objetiva entre el trabajo y el capital que a una causa primera de carácter intemporal.

\footnotetext{
-es decir, se muestra favorable al cumplimiento de las promesas de autonomía y autorrealización que la Ilustración consideraba exigencias éticas fundamentales-, esencialmente con respecto a dos perspectivas derivadas de la primacía otorgada al mercado: la posibilidad de elegir tanto el estado social (profesión, lugar y modos de vida, relaciones, etc.) como los bines y servicios poseídos o consumidos», BOLTANSKI, L. \& CHIAPELLO, E.: El nuevo espíritu del capitalismo, Ed. Akal, Madrid, 2002, p. 535.

31 «Esos trabajadores irlandeses que, por 4 peniques (31/3 groschen de plata), hacen la travesía hacinados como ganado y se instalan por todas partes. Las peores viviendas son suficientemente buenas para ellos; la ropa es harapienta; ignoran el uso del calzado; su alimentación consiste únicamente de papas, lo que ganan extra se lo gastan en bebida». ENGELS, F., "La situación de la clase obrera en Inglaterra», Ed Progreso, Moscú, 1979, p. 151.

32 Confert. COTARElO GARCíA, R., «Los precursores de la Teoría socialista: SaintSimon, Charles Fourier, Robert Owen», en TEZANOS, J.F., Teoría política del socialismo, Ed. Sistema, Madrid, 1993, pp. 27-44.
} 
Hemos de señalar también que no solo la idea de «libertad» de raigambre francesa ha impregnado la ideología decimonónica sino también la de «igualdad». En este sentido los autores anteriormente citados también reconocen que el desarrollo de la igualdad debe pasar de ser un marco exclusivamente jurídico/formal y materializarse de forma real y para ello es necesario una nueva concepción de la distribución de la riqueza/producción pues en tanto que esta siga siendo desigualitaria no puede más que darse, al menos es la tesis de Marx al respecto, más que un derecho aparentemente igualitario pero, en el fondo, profundamente desigualitario ${ }^{33}$. No creemos equivocarnos si entendemos que no fue fruto de una mera casualidad que los Pioneros de Rochdale se auto-denominaron igualitarios (Rochdale Equitable Pioneers Society) con la intención de remarcar la apuesta por la igualdad material frente a la igualdad formal.

Por último no hemos de olvidad, para completar la tríada de ideales de la Revolución Francesa, el concepto de «fraternidad» que presupone al menos si nos atenemos a su raíz etimológica la concepción de un cierto «hermanamiento» de los seres humanos. Es por ello que algunos de los ideólogos del cooperativismo se movían en planteamientos con base religiosa o al menos desde la perspectiva de una visión trascendente del hombre que, en su base, determinaba la raíz común de los mismos. En estas coordenadas podemos enmarcar el Nuevo Cristianismo que Saint Simon escribe en 1825 donde aboga por una nueva interpretación de la religión cristiana basada en los principios de igual-

33 «Pero unos individuos son superiores, física e intelectualmente a otros y rinden, pues, en el mismo tiempo, más trabajo, o pueden trabajar más tiempo; y el trabajo, para servir de medida, tiene que determinarse en cuanto a duración o intensidad; de otro modo, deja de ser una medida. Este derecho igual es un derecho desigual para trabajo desigual. No reconoce ninguna distinción de clase, porque aquí cada individuo no es más que un trabajador como los demás; pero reconoce, tácitamente, como otros tantos privilegios naturales, las desiguales aptitudes individuales, y, por consiguiente, la desigual capacidad de rendimiento. En el fondo es, por tanto, como todo derecho, el derecho de la desigualdad. El derecho sólo puede consistir, por naturaleza, en la aplicación de una medida igual; pero los individuos desiguales (y no serían distintos individuos si no fuesen desiguales) sólo pueden medirse por la misma medida siempre y cuando que se les coloque bajo un mismo punto de vista y se les mire solamente en un aspecto determinado; por ejemplo, en el caso dado, sólo en cuanto obreros, y no se vea en ellos ninguna otra cosa, es decir, se prescinda de todo lo demás. Prosigamos: un obrero está casado y otro no; uno tiene más hijos que otro, etc., etc. A igual trabajo $y$, por consiguiente, a igual participación en el fondo social de consumo, uno obtiene de hecho más que otro, uno es más rico que otro, etc. Para evitar todos estos inconvenientes, el derecho no tendría que ser igual, sino desigual». MARX, K.: "Crítica del Programa de Gotha», Obras Escogidas en 3 vol. (Vol. III), Ed. Progreso, Moscú, 1977, p. 6. 
dad iniciales determinados por el origen común de todos los hombres para afirmar la hermandad de los mismos ${ }^{34}$.

De este modo es en este contexto en el que puede aparecer un modelo empresarial de las características cooperativas pues la cristalización ideológica de las ideas fuerza de la revolución francesa ha propiciado la posibilidad material de un planteamiento como el del cooperativismo empresarial. De este modo una serie de tejedores fundaron en 1844 la primera cooperativa en sentido formal ya que la ideología de los individuos fundadores (en su mayoría cartistas y socialistas) se encontraba fundamentada/determinada por las condiciones materiales de vida producidas en dicha época, incluyendo por supuesto, las ideológicas de la Revolución Francesa.

\subsection{Líneas genéricas (ensayo) de reconstrucción de los Principios Cooperativos}

Los Pioneros de Rochdale, tal y como hemos mostrado, fueron los fundadores de la primera cooperativa empresarial en sentido formal y a ellos les debemos también la formulación de los principios cooperativos que a modo de ideario estratégico-valorativo regularon su actividad empresarial ${ }^{35}$. Ahora bien, dichos principios (y valores) cooperati-

34 «La nueva organización cristiana basará las instituciones temporales y espirituales en el mismo principio todos los hombres deberían tratarse entre sí como hermanos. Dirigiré todas las instituciones, sea cual sea su naturaleza, a incrementar el bienestar de la clase más pobre. Tengo, por tanto, una clara concepción de la nueva doctrina cristiana, y la desarrollaré. Voy a revisar todas las instituciones en Inglaterra, Francia, Alemania del norte y el sur, Italia, España, Rusia y América del Norte y del Sur. Compararé las doctrinas de estas instituciones con la doctrina dedicada directamente del principio fundamental de la moral divina, y convenceré fácilmente a todos los hombres de buena fe $y$ buena voluntad de que si todas estas instituciones estuvieran dirigidas a mejorar el bienestar moral y físico de la clase más pobre, proporcionarían con la mayor rapidez prosperidad a todas las clase de la sociedad y a todas las naciones». SAINT SIMON, H.: El nuevo cristianismo, Ed. Biblos, Buenos Aires, 2004, p. 37.

35 Somos conscientes de que esta tesis es un poco controvertida en la medida en que hay autores que defienden que las bases de Rochdale las encontraríamos ya en Buchez y que por lo tanto la primera cooperativa sería la fundada por este: "[ ] otra experiencia cooperativa de indudable interés es la constituida por l'Association Chrétienne des Bijoutiers en Doré, cooperativa de trabajo asociado creada en París en 1834 por inspiración de Jean-Philippe Buchez y que tuvo actividad durante 39 años. Para Buchez, que se adelantó en muchos aspectos a los pioneros de Rochdale, la cooperativa de trabajo es una asociación completamente diferente a las sociedades comerciales o industriales [...] parece claro que en la concepción cooperativa de Buchez están diseñadas las reglas más importantes, tanto de la cooperación de trabajo como de otras clases de 
vos no son entendibles al margen de la realidad que hemos descrito en el punto anterior. Es decir, los principios y valores no se deben entender, tal es nuestra tesis, al margen de las propias condiciones materiales en las que han sido formulados. En este sentido, cobra vital importancia los presupuestos de partida que hemos utilizado en la medida en que «exigen» el tratamiento de dichos principios a partir de dichos presupuestos.

En este sentido los principios (y valores) establecidos por los pioneros de Rochdale han surgido en un determinado contexto histórico y se han formulado por oposición o conflicto dialéctico con otros principios. En este caso, dichos principios cooperativos son construidos por oposición dialéctica a los principios de la empresa capitalista industrial tradicional que se desarrolla a lo largo de siglo XIX.

Por este motivo debemos recuperar la idea antes establecida en el plano biológico y de teoría de juegos del desarrollo de la estrategia cooperativa como un alternativa supervivencial frente a otras en un contexto de contradicción laboral y conflicto entre el capital y el trabajo $^{36}$. Al igual que las especies, tal y como reconocía parcialmente

cooperativas. Los principios de Rochdale, enunciados 10 años más tarde descansarán en planteamientos sustancialmente idénticos a los buchecianos». MONZÓN CAMPOS, J.L., "Las cooperativas de trabajo asociado ante la reforma de los principios cooperativos», REVESCO, Revista de estudios cooperativos, n. ${ }^{\circ} 61,1995$, pp. 47-52, p. 48.

36 Los contextos de crisis laboral, como es bien sabido, en las que un empresario se ve obligado, por las razones que fueren, a prescindir de su empresa y esta es adquirida por los trabajadores en forma de cooperativa es una realidad muy frecuente: «[...] el primer Arizmendiarrieta comprenderá la crisis que ha estallado ya en dos guerras mundiales, no como una crisis circunstancial o parcial (económica, por ejemplo)sino como la crisis de los mismos fundamentos de una civilización, con todos sus principios y valores, que empezando por divinizar al hombre, ha acabado por consagrar la esclavitud del hombre por el hombre o su anulación en el océano colectivista». AZURMENDI, J., El hombre cooperativo: pensamiento de Arizmendiarrieta, Ed. Azatza, San Sebastián, 1992, pp. 107-108. Habría que considerar a propósito de esta cuestión que son las circunstancias existentes en Mondragón en el año 50 las que provocan en Arizmendiarrieta la necesidad de la estrategia cooperativa, dado que Arizmendiarrieta llega en el año 1941 a Mondragón y hasta el año 1954 no se coloca la primera piedra de ULGOR: «El hecho determinante que había de dar lugar a la puesta en marcha de la primera piedra del edificio hoy constituido como MCC, se encuentra inequívocamente en la llegada a Mondragón de un joven sacerdote llamado D. José María Arizmendiarrieta. Tal fue la capacidad movilizadora de aquel sacerdote joven, 26 años entonces, dinámico, emprendedor, cargado de ideas, que en 1941 llega a Mondragón para hacerse cargo de la juventud de la parroquia. Desde su llegada hasta la aparición de la primera empresa productiva (Talleres Ulgor, hoy Fagor electrodomésticos) transcurren nada menos que catorce años, lo que quiere decir que en su ánimo no hay una idea preconcebida de desarrollo empresarial y sí de preocupación por las personas, porque existan opciones para todos y se satisfagan las carencias sociales enormemente acusadas en una población 
Kropotkin, establecen mecanismos de ayuda mutua o cooperación frente a terceros, nos encontramos que en el caso del surgimiento de las cooperativas ocurre, como decimos, algo análogo.

En Rochdale se establecen por primera vez unos principios cooperativos $^{37}$ que, a nuestro juicio y por lo que venimos argumentando, son el resultado dialéctico de respuesta a las condiciones materiales de vida, la implantación de la tríada ideológica de la Revolución Francesa y la situación de búsqueda de estrategias empresariales frente a la empresa capitalista. En este sentido, los principios rochdalianos reflejan el carácter de la primacía e importancia del trabajo frente al capital en cuanto a la redistribución de los beneficios y la articulación del entramado de gestión de la empresa. Hemos de recuperar en este momento el concepto de contradicción inherente a la idea nuclear de la cooperación en el caso específico de la contradicción entre el capital y el trabajo tal y como fue señalada, por ejemplo, por Marx. Desde este punto de vista el sistema de producción capitalista estaba determinado por una contradicción «objetiva» entre los beneficios del trabajo, su distribución y las fuerzas productivas. De tal forma que capital y trabajo no se correspondían de una forma equilibrada o «justa» sino que más bien el carácter social de la producción se contradice con la apropiación privada de los beneficios de la misma ${ }^{38}$.

que vive las consecuencias desastrosas de la guerra civil». UGARTE AZPIRI, L.M., "Mondragón Corporación Cooperativa «Historia de una experiencia», Revista de Estudios de Juventud, n. 51, 2001, pp. 25-36, p. 25-26 En este contexto se situaría también el origen de Gredos-San Diego Sociedad Cooperativa cuyo origen se da en un fuerte contexto de crisis laboral (año 1985) y por el abandono por parte del colegio origen de su anterior propietario, 18 trabajadores deciden emprender el camino del cooperativismo empresarial: "El cooperativismo era solo un término, una palabra de significado tan deseado como desconocido. Nos lo mostraban como herramienta no solo para garantizar el trabajo de todos, sino para perpetuar una empresa que había tocado fondo, que había llegado a una situación límite: descapitalización total, deterioro de las instalaciones e imposibilidad absoluta de cualquier intento de rehabilitación; mobiliario prácticamente destruido; soterrada amenaza de ver cómo podría disminuir el alumnado por causas ya aludidas (descenso de la natalidad, remodelación, o elección de los padres de otros centros públicos o privados )». GARCíA GONZÁLEZ, J., 25 años forjando sueños, Ed. Gredos San Diego Cooperativa, Madrid, 2010, p. 124.

37 1. Libre adhesión, 2. Control democrático, 3. Devolución o bonificación sobre las compras, 4. Interés limitado al capital, 5. Neutralidad política y religiosa, 6. Ventas al contado, 7. Fomento de la enseñanza.

38 «Tomemos un obrero cualquiera, un tejedor, por ejemplo. El capitalista le suministra el telar y el hilo. El tejedor se pone a trabajar y el hilo se convierte en lienzo. El capitalista se adueña del lienzo y lo vende en veinte marcos, por ejemplo. ¿Acaso el salario del tejedor representa una parte del lienzo, de los veinte marcos, del producto de su trabajo? Nada de eso. El tejedor recibe su salario mucho antes de venderse el lienzo, tal 
De este modo no es casual sino estructural que en el preámbulo de sus Estatutos y Fines constitutivos de Rochdale se reconozca que la sociedad (empresa) se constituye con la obligatoriedad ya no solamente de servir como sustento económico sino prácticamente como forma para mejorar las condiciones generales de vida, no solo económicas sino también de vivienda, educación y acceso al trabajo en condiciones de libre adhesión. De este modo al final de su art. 1 se establece que: «Desde el momento que sea posible, esta sociedad emprenderá la organización de las fuerzas de la producción, de la distribución de la educación y del gobierno, o, dicho en otras palabras, el establecimiento de una colonia que se baste a sí misma y en la que se unirán los intereses, o bien prestará ayuda a otras sociedades para establecer colonias de esa clase».

Los trabajadores de Rochdale entendieron el modelo empresarial cooperativo como una forma ya no solo de acceso de los trabajadores a los medios de producción (por utilizar la fórmula del 129.2 de la CE) sino del acceso a una mejora progresiva de sus condiciones materiales de vida. Mencionan en sus estatutos la construcción de viviendas que mejoren las existentes, campos de cultivo para trabajadores desempleados y por supuesto no dejan al margen de dichas mejoras unos estrictos mecanismos de control de las finanzas así como el principio de distribución de los cargos del Consejo a través de un mecanismo democrático y no basado en el capital de los individuos, pues por definición, el capital social de la empresa se forma por la aportación obligatoria en condiciones de igualdad.

vez mucho antes de que haya acabado el tejido. Por tanto, el capitalista no paga este [156] salario con el dinero que ha de obtener del lienzo, sino de un fondo de dinero que tiene en reserva. Las mercancías entregadas al tejedor a cambio de la suya, de la fuerza de trabajo, no son productos de su trabajo, del mismo modo que no lo son el telar y el hilo que el burgués le ha suministrado. Podría ocurrir que el burgués no encontrase ningún comprador para su lienzo. Podría ocurrir también que no se reembolsase con el producto de su venta ni el salario pagado. Y puede ocurrir también que lo venda muy ventajosamente, en comparación con el salario del tejedor. Al tejedor todo esto le tiene sin cuidado. El capitalista, con una parte de la fortuna de que dispone, de su capital, compra la fuerza de trabajo del tejedor, exactamente lo mismo que con otra parte de la fortuna ha comprado las materias primas - el hilo- y el instrumento de trabajo - el telar-. Una vez hechas estas compras, entre las que figura la de la fuerza de trabajo necesaria para elaborar el lienzo, el capitalista produce ya con materias primas e instrumentos de trabajo de su exclusiva pertenencia. Entre los instrumentos de trabajo va incluido también, naturalmente, nuestro buen tejedor, que participa en el producto o en el precio del producto en la misma medida que el telar; es decir, absolutamente en nada». MARX, K., "Trabajo asalariado y capital», Obras Escogidas en 3 vol. (Vol. I) Ed. Progreso, Moscú, 1977, pp. 156-157. 
Rochdale es, en este sentido, la primera forma empresarial cooperativa que en sus principios estructura un modelo alternativo a la forma de organización empresarial capitalista tal y como, por ejemplo, Marx supo ver aunque bajo una forma o momento del desarrollo de las fuerzas productivas que terminaría desembocando en la sociedad comunista ${ }^{39}$.

Los principios de Rochdale fueron y han sido ampliamente discutidos y en algunos casos reformulados o reconstruidos por las diferentes propuestas a lo largo de su historia por parte de la Alianza Cooperativa Internacional ${ }^{40}$. Desde nuestra interpretación de los principios cooperativos y el sentido del surgimiento de los mismos sería conveniente analizar pormenorizadamente las variaciones históricas en la formulación, reformulación o adicción de dichos principios. A nuestro juicio dichas variaciones se deben a las variaciones en las condiciones materiales históricas, políticas, económicas (categoriales en el sentido expuesto al principio del trabajo) en cuyo desarrollo encontramos el origen de los valores y principios y de las ideas o conceptos que rigen ideológicamente a los grupos humanos. Dado que la tarea de reconstrucción de dichas variaciones rebasa los límites de este trabajo, nos parece oportuno analizar solo algún aspecto llamativo para mostrar cuál sería desde nuestras categorías la interpretación de dicho desarrollo.

39 "Las fábricas cooperativas de los obreros mismos son, dentro de la forma tradicional, la primera brecha abierta en ella, a pesar de que, donde quiera que existan, su organización efectiva presenta, naturalmente y no puede menos que presentar, todos los defectos del sistema existente. Pero dentro de estas fábricas aparece abolido el antagonismo entre el capital y el trabajo, aunque, por el momento, solamente bajo una forma en que los obreros asociados son sus propios capitalistas, es decir, emplean los medios de producción para valorizar su propio trabajo. Estas fábricas demuestran cómo al llegar a una determinada fase de desarrollo de las fuerzas materiales producidas y de las formas sociales de producción adecuadas a ellas, del seno de un régimen de producción surge y se desarrolla naturalmente otro nuevo. Sin el sistema fabril derivado del régimen capitalista de producción no se hubieran podido desarrollar las fábricas cooperativas, y mucho menos sin el sistema de crédito, fruto del mismo régimen de producción. El sistema de crédito, base fundamental para la gradual transformación de las empresas privadas capitalistas en sociedades anónimas capitalistas, constituye también el medio para la extensión paulatina de las empresas cooperativas en una escala más o menos nacional. Las empresas capitalistas por acciones deben ser consideradas al igual que las fábricas cooperativas, como formas de transición entre el régimen capitalista de producción y el de producción asociadas; la única diferencia es que en un caso el antagonismo aparece abolido negativamente, mientras que en el otro aparece abolido en sentido positivo». MARX, K., El Capital, Tomo III, F.C.E., México, 1968, p. 418.

40 Confert. BALLESTERO, E.: Economía social y empresas cooperativas, Ed. Alianza, Madrid, 1990, p. 161 y ss. 
En el XV Congreso de la ACl celebrado en Paris en el año 1937 se formulan los principios cooperativos necesarios para la constitución de empresas cooperativas así como la pertenencia como miembro a la propia $\mathrm{ACl}$. Estos principios son: libre adhesión, control democrático, distribución a los socios del excedente a prorrata de sus compras y el interés limitado del capital. Como principios de carácter secundario se formulaban la neutralidad política y religiosa, la venta al contado y el desarrollo de la educación los cuales no resultaban necesarios para ser una cooperativa reconocida, era suficiente cumplir los primarios, y formar parte de la $\mathrm{ACl}$.

Es evidente que el carácter mínimo de los principios necesarios se lleva a cabo por parte de la $\mathrm{ACl}$ de una forma condicionada por las circunstancias y la necesidad de incorporar en la Alianza al mayor número de sociedades posibles. En el año 1966, en Viena, desaparece el principio de neutralidad política y religiosa y se incluye en su Primer Principio dicha no discriminación pero aplicada más a las personas que a las empresas ("La adhesión a una sociedad cooperativa debe ser voluntaria y abierta a todas las personas que puedan hacer uso de sus servicios y acepten las responsabilidades inherentes a su afiliación; no debe haber restricciones artificiales ni discriminaciones sociales, politicas o religiosas») y en este sentido se podían incluir como miembros de derecho de la $\mathrm{ACl}$ las cooperativas existentes en las países de economía planificada que tenían un control de la gestión y organización de las cooperativas respectivas por parte del Estado. A pesar de esta situación fueron, como decimos, reconocidas como miembros de la $\mathrm{ACl}^{41}$.

Ahora bien, la caída de los sistemas de economía planificada determinó en el Congreso de Manchester de 1995 la inclusión novedosa del principio de Autonomía e Independencia como una forma de recono-

41 En la antigua Unión Soviética se llegó a aprobar una ley que permitió, en el año 1988, la creación de cooperativas sin intervención del Estado pero su viabilidad resultó harto complicada: «En 1988, la antigua URSS adoptó una legislación cooperativa en la que se preveía la creación de nuevas cooperativas autónomas, con una composición mínima de tres miembros, que constituyeron la primera expresión legítima de empresas privadas, pese a que sólo podían actuar en una serie restringida de sectores (proveedores de servicios y restaurantes). Ante la ausencia de mecanismos de control eficaces, esta oportunidad se utilizó en gran medida para legalizar actividades comerciales no estructuradas e ilegales, y para llevar a cabo actividades con fines lucrativos. Ahora bien, aunque se legalizaron las actividades cooperativas, las nuevas cooperativas estaban sujetas a graves restricciones, tales como impuestos elevados y medidas burocráticas heredadas de la administración comunista (por ejemplo, las restricciones a la propiedad privada de la tierra, a los préstamos, a las materias primas y a las piezas de repuesto)». Informe $V$, del quinto punto del orden del día «Promoción de las Cooperativas» de la 89a reunión de trabajo de la OIT celebrada en Junio de 2001. 
cimiento de las mismas como entidades que pueden operar con cualquier tipo de institución o gobierno siempre y cuando mantengan dicho principio directivo en un mundo cada vez más globalizado dentro de una economía de mercado capitalista ${ }^{42}$. De este modo podemos observar cómo la evolución de los principios cooperativos es pareja a la evolución en la forma de las relaciones entre categorías y conceptos o ideas que hemos planteado en los principios de partida. Insistimos en que sería muy interesante, aunque rebase los límites del presente trabajo, realizar una reconstrucción completa de la historia de la evolución, transformación y desarrollo de los principios cooperativos ${ }^{43}$ asociados a los presupuestos metodológicos propuestos en el presente

42 «Este principio no se recogió explícitamente en la formulación de1996. En ese momento, la ACl adoptó una posición más condescendiente para evitar la salida de la entidad internacional de los países de regímenes comunistas, dado que limitaban la autonomía e independencia de sus cooperativas. Ahora, tras la caída de tales regímenes, la ACl vuelve hacia la posición de 1937, época en la que consagró como uno de los principios la «neutralidad política y religiosa». Sin embargo, lo más novedoso en la formulación de este principio es la referencia a la firma de acuerdos «con otras organizaciones». Con ella se reconoce el hecho de que, en todo el mundo, cada vez más cooperativas están entrando en proyectos conjuntos con otras empresas del sector privado, aunque se señala la importancia de que éstas mantengan la libertad de controlar su propio destino futuro al negociar tales acuerdos». GADEA SOLER, E., "Estudio sobre el concepto de cooperativa: Referencia a los principios cooperativos y su discutida vigencia», JADO: boletín de la Academia Vasca de Derecho, n. ${ }^{\circ}$ 17, año 7, 2009, pp.168-185, p. 181. En este sentido se reconoce por parte de MONZÓN CAMPOS que: "De los anteriores principios dos de ellos son nuevos, a saber, el 4. ${ }^{\circ}$, de autonomía e independencia y el $7 .^{\circ}$, de interés por la Comunidad, siendo una de las reformas más importantes la que tiene que ver con el 4. ${ }^{\circ}$ principio. En efecto, en la explicación de motivos de dicho principio se reconoce que las cooperativas se integran, cada vez más en proyectos mixtos con organizaciones capitalistas. El principio, tal y como está formulado, reconoce también la posibilidad de contar entre los socios cooperativos a inversores capitalistas, siempre que se asegure el control democrático de la cooperativa por los socios usuarios», "Las cooperativas de trabajo asociado ante la reforma de los principios cooperativos», op. cit., pp. 49-50.

43 Y consiguientemente el propio concepto de cooperativa y su finalidad empresarial. Compárese la concepción actual de las cooperativas con la promulgada, por ejemplo, en la Conferencia de Federaciones (donde concurren sindicalistas y cooperativistas) celebrada en el año 1920 en Valencia según la cual: «la finalidad perseguida por medio del cooperativismo es, mediante la cooperación de consumo hoy, y de producción y otras formas mañana, poner en manos del proletariado en colectividad el capital, tierras, fabricación, herramientas y útiles de trabajo para la creación de la riqueza colectiva, haciendo imposible las funciones del intermediario y de la burguesía, hasta lograr la desaparición completa del capitalismo, acabando con la explotación del hombre por el hombre y de todos los privilegios, dejando de ser el obrero una cosa materia de explotación, recobrando su total personalidad humana y obteniendo íntegro el fruto de su trabajo dentro de un estado de derecho, inspirado en la libertad estricta y la justicia para que su vida sea feliz en grado máximo». REVENTÓS, J.: El movimiento cooperativo en España, op. cit., p. 134 [nota a pie 33]. 
trabajo pues de este modo podríamos entender a estos como directamente relacionados con las condiciones categoriales del devenir histórico.

\section{El futuro y el papel crítico de la empresa cooperativa en el siglo XXI}

Una vez desentrañado tanto el núcleo como las líneas generales de desarrollo histórico del movimiento cooperativo a partir del núcleo nos resta, por último, tratar de delimitar o en su caso interpretar el cooperativismo como movimiento empresarial actual en el contexto de la sociedad de mercado capitalista del presente ${ }^{44}$. Nuestra interpretación de dicha situación será dependiente de lo que hemos establecido como núcleo del cooperativismo empresarial y la situación del mismo con respecto a otros modelos empresariales realmente existentes y presentes. Para ello, entendemos que es necesario explicar al menos en un sentido genérico el carácter o estructura de la sociedad presente en sus ámbitos económicos, sociales y políticos para posteriormente entender el papel que juega realmente la empresa cooperativa en la misma e incluso sus posibles líneas de fortaleza con respecto a otros modelos empresariales.

A nuestro juicio, y sin poder entrar en demasiados detalles al respecto, la situación geopolítica de restructuración del mundo que se produce a partir de la desmembración de la antigua Unión Soviética determina las líneas generales de la distribución política y económica de la sociedad presente. La desaparición del Ilamado, en expresión de Rudolf Bahro, "socialismo realmente existente» determinó la definitiva instauración hegemónica del orden capitalista a nivel global y la

44 Como definición de «mínimos» nos parece esencialmente correcta la formulada por Boltanski y Chiapello: "De las diferentes caracterizaciones del capitalismo realizadas desde hace un siglo y medio retendremos una fórmula mínima que hace hincapié en la exigencia de acumulación ilimitada de capital mediante medios formalmente pacíficos. La perpetua puesta en circulación del capital dentro del circuito económico con el objetivo de extraer beneficios, es decir, de incrementar el capital que será a su vez reinvertido de nuevo, sería lo que caracterizaría primordialmente al capitalismo [...] las formas concretas de la riqueza no tienen interés en sí y pueden suponer incluso, debido a su falta de liquidez, un obstáculo para el único objetivo realmente importante: la transformación permanente del capital, de los bienes de equipo $y$ de las distintas adquisiciones en producción, de la producción en dinero y del dinero en nuevas inversiones». BOLTANSKI, L. \& CHIAPELLO, E.: El nuevo espíritu del capitalismo, op. cit., 2002, p. 35. 
consiguiente globalización en forma de extensión paulatina de dicho orden. El cooperativismo o en general la economía social se han entendido, en este contexto, como una alternativa en forma de tercera vía empresarial frente a la economía planificada y el liberalismo económico ${ }^{45}$.

Ahora bien, tal y como hemos defendido a lo largo de este trabajo, el proceso de desarrollo de los principios del cooperativismo así como su forma empresarial específica no son, ni pueden ser según nuestro planteamiento, impermeables a estos acontecimientos histórico-políticos. La empresa cooperativa se ha situado, dado su núcleo o naturaleza, de forma equidistante frente a estos dos modelos económico-políticos asumiendo que su posición debía mostrar puntos de equilibrio tal y como hemos descrito en el comentario anterior que hemos realizado sobre la aparición, desarrollo o reconstrucción de los principios cooperativos.

Sin perjuicio de lo anterior, a nuestro juicio, el cooperativismo empresarial se presentaba en tiempos del mundo bipolar como una alternativa que reconocía el valor del trabajo humano por encima del capital (economía planificada) y a la vez la autonomía e independencia del poder estatal (liberalismo económico). Ahora bien, la empresa cooperativa desde la desaparición de la economía planificada va a adoptar un nuevo papel en el conjunto de la sociedad capitalista. La desaparición los sistemas de economía planificada donde, al menos en principio, no figuraba el capital como motor del desarrollo del trabajo por encima de los individuos, ha determinado que la única forma empresarial realmente existente donde se conjuga participación democrática y primacía del factor trabajo sobre el capital sean las empresas pertenecientes a la Economía Social y particularmente las empresas cooperativas.

Ahora bien, cuál o cuáles son las razones por las cuales el cooperativismo se ha mantenido de forma ininterrumpida desde su aparición en Rochdale como una forma empresarial con continuidad pese a los diferentes momentos históricos y aún la existencia de los divergentes y antagónicos sistemas productivos. En general se suele defender la tesis

45 «El cooperativismo es un sistema ordenador de la vida en sociedad, no solo una mera forma de empresa. Aunque a los acomodados no les agrade, es ciertamente (o mejor, puede serlo) la «medianera» entre el capitalismo y los estatalismos económicos, pudiendo servir como instituto corrector de un capitalismo sin participación, para asi llegar a una democracia plena, política y económica, en la auténtica base constitucional de una economía de social de mercado». DIVAR, J.: Las cooperativas: una alternativa económica, Ed. Dykinson, Madrid, 2011, P. 141. 
según la cual tanto un sistema como otro (economía planificada o capitalismo) han utilizado a la empresa cooperativa y en general a la economía social como una herramienta al servicio de aquellas necesidades que por diversas razones dichos sistemas no pudiesen atender. En este sentido la Economía Social habría sido un elemento esencial a ambos modelos productivos pues se materializaba su presencia en el vacío productivo que ambos sistemas no podían cubrir.

Ahora bien, esta interpretación, aun siendo en parte verdadera, olvida la naturaleza de la empresa cooperativa que no es tanto su actividad instrumental para el "mantenimiento del sistema» cuanto su actividad, aun dentro del sistema, desde un determinado planteamiento empresarial de principios y valores, los cuales lejos de tener un carácter instrumental mantienen y garantizan la forma empresarial diferenciada que encarna el cooperativismo. Por lo tanto la supervivencia de la empresa cooperativa se debe más a su naturaleza que al uso instrumental por parte del sistema económico-productivo en que esté inserta ${ }^{46}$.

Por lo tanto, y precisamente por la relativa independencia del sistema económico en el que opera la empresa cooperativa no estará, en principio, sujeta a las determinaciones de dicho sistema. Por ejemplo en cuanto a las políticas empresariales de disminución de la producción en tiempos de crisis (aunque no necesariamente en estos pues también se practican regulaciones de empleo o despidos en empresas con cuentas de resultados positivas). Frente a la práctica imposibilidad de reestructuración por parte de las empresas tradicionales que, en un determinado momento de disminución de la producción o no alcance de beneficios esperados, liquidan la sociedad o practican regulaciones en el empleo, la empresa cooperativa tiene la capacidad, pues se encuentra determinada por la primacía del hombre sobre el capital, de re-estructurarse o reorganizarse pues se encuentra en su propia naturaleza constitutiva.

Volvamos en este momento a uno de los momentos de construcción de nuestro trabajo el que hemos analizado de forma crítica las te-

46 «La capacidad de las cooperativas, y sus socios, de asumir objetivos más amplios a los económicos, incluyendo aspectos sociales y medioambientales, dada la estructura objetivo que manifiesta una estructura organizacional centrada en las personas y sus objetivos comunes. En este sentido, cobra valor el rol que cumplen en la creación de valor social, característica asociada a las empresas de economía social, siendo parte del segmento de organizaciones participantes en la economía de mercado». MARCUELLO, C. \& NACHAR-CALDERÓN, P.: «Sociedad cooperativa y socio cooperativo: propuesta de sus funciones objetivo», Documentos de trabajo (Universidad de Zaragoza, Facultad de Economía y empresa), n. ${ }^{\circ} 2,2012$, p. 17. 
sis de Kropotkin. La capacidad biológico-evolutiva de reestructuración tanto de las especies como de los organismos en particular ante amenazas externas determina su posibilidad de supervivencia y en este sentido dado que la cuestión biológica la hemos incluido en la raíz de la idea nuclear de cooperación afirmamos que las empresas que están constituidas con dichos principios son más proclives a dichas reestructuraciones por su naturaleza que aquellas que se mantienen bajo el principio de sociedades de capital.

La reestructuración que se produce en los grupos animales al llevar a cabo, frente a terceros, estrategias de cooperación que les permiten tener éxito determina la posibilidad en el tiempo de seguir re-estructurándose ante una eventual amenaza futura que si no desarrollan dichas estrategias. Análogamente, en un sentido empresarial, las empresas cooperativas dada su naturaleza en cuanto a la estrategia de constitución y gestión permite igualmente, en el tiempo, adoptar diferentes estrategias ante posibles riesgos externos ${ }^{47}$.

A esta cuestión hemos de añadir, por reforzar nuestra posición en este sentido, la conclusión general que se desprendía de la teoría de juegos con respecto a la toma de decisión de carácter cooperativo frente a la individualista-particular en cuanto estrategia que tenía más garantías de éxito a largo plazo y no solo en este sentido sino también en cuanto a la mayor probabilidad de incremento del beneficio para el

47 Son a nuestro juicio absolutamente esclarecedoras de esta idea las conclusiones en forma de datos objetivos que se presentan en el artículo/informe presentado por la revista CIRIEC en el año 2012 relativas tanto a los salarios como a la empleabilidad y la sensibilidad social: "[] las cooperativas han tenido, en la situación de crisis actual, una mayor capacidad de incorporación entre sus plantillas, tanto a personas desempleadas, como a individuos que trabajaban en otro tipo de empresas. Las diferencias en este último aspecto entre las cooperativas y las empresas capitalistas son bastante considerables. Lo que vendría a corroborar el planteamiento del segundo enfoque teórico de que la crisis económica aumenta el potencial expansivo de las entidades de la economía social y su capacidad de generación de empleo. Esto queda justificado por dos procesos simultáneos: por la transformación de empresas tradicionales en crisis en empresas de la economía social; y porque los parados y colectivos con problemas de inserción laboral ven en la creación de una entidad de economía social o su integración laboral en ella, una vía para conseguir un empleo. En definitiva, el comportamiento diferencial que presentan las cooperativas frente a la empresas capitalistas con respecto al grado de integración entre sus plantillas, tanto de desempleados como de personas procedentes de otro tipo de empresas, sería la causa fundamental que permite justificar la menor sensibilidad de las cooperativas al desempleo en la situación de crisis actual». CALDERÓN MILÁN, B \& CALDERÓN MILÁN, M.J.: «Cómo afrontan la crisis las cooperativas en España: comparativa de trayectorias laborales a partir de la Muestra Continua de Vidas Laborales», Rev. CIRIEC España de Economía Social, Pública y Cooperativa, n. 76, Diciembre 2012, pp. 5-26, p.24. 
propio individuo particular ${ }^{48}$. De este modo la forma empresarial cooperativa, por su naturaleza y como estamos viendo en este momento por sus resultados empresariales y laborales realmente existentes, se nos muestra como una forma que resiste mejor que otras a las posibles crisis económicas y aun a posibles reajustes no directamente relacionados con la crisis sino con los beneficios proyectados en el plan de negocio.

Se desprende de esta apuesta nuclear del cooperativismo por la igualdad y los valores sociales que el alcance de estos ha impregnado paulatinamente, sobre todo a partir de los años 90, las políticas empresariales tradicionales de la sociedad de mercado. Algunas de esas empresas han incorporado en sus estrategias empresariales la llamada Responsabilidad Social Empresarial, en la que indudablemente han influido los principios y valores de la empresa cooperativa. Es decir, frente a la concepción neoliberal encarnada por M. Friedman, y en general la llamada Escuela económica de Chicago, para los que la única responsabilidad social de la empresa es el incremento de beneficios para sus accionistas ${ }^{49}$, algunas empresas han optado por la práctica de políticas de

48 «For an example of an extended cooperative solution in this sense, see McCain (2007). This is a "game» of effort determination in a cooperative enterprise, in which productive efficiency requires an effort commitment by each individual that is greater than the commitment the personwould choose on the basis of pure self-interest in a noncooperative solution of the "game.» Suppose that there is a norm of effort commitment, and suppose that the norm is the effort commitment required for efficient production. If one member makes effort less than the norm then other members perceive this as an unfriendly act and retaliate (perhaps by shunning or «putting in Coventry, " though McCain is not explicit on this). Reciprocity motives lead to one or the other of two "solutions»: in one, everyone obeys the norm, production is efficient, and there is no retaliation. The other solution recapitulates the noncooperative one: everyone chooses the effort commitment on the basis of self-interest, without regard to social norms, and, each being equally a slacker, there is again no retaliation. 14 The "cooperative» norms, in this case, are the ones required for efficient production, which also defines the common strategy. In this model, equal sharing of work time and pay are assumed throughout». MCCAIN, R.A.: "Cooperative games and cooperative organizations», The Journal Socio-Economics, 37, 2008, pp.2155-2167, p. 2165

49 "But the doctrine of «social responsibility» taken seriously would extend the scope of the political mechanism to every human activity. It does not differ in philosophy from the most explicitly collectivist doctrine. It differs only by professing to believe that collectivist ends can be attained without collectivist means. That is why, in my book Capitalism and Freedom, I have called it a "fundamentally subversive doctrine» in a free society, and have said that in such a society, "there is one and only one social responsibility of business-to use it resources and engage in activities designed to increase its profits so long as it stays within the rules of the game, which is to say, engages in open and free competition without deception or fraud.» FRIEDMAN, M., «The Social Responsibility of Business is to Increase its Profits», The New York Times Magazine, 1970. 
RSE deudoras de valores humanistas tradicionales encarnados en la naturaleza de la empresa cooperativa ${ }^{50}$.

En definitiva, nos parece que por estas razones anteriores las cooperativas deben llevar a cabo, sin prejuicio de su operatividad y realidad como empresas, la crítica constante al modelo en el cual el capital se encuentra por encima de los individuos. Y todo ello, insistimos, sin perjuicio de su operatividad como empresas en cuanto a la producción y cuenta de resultados. En este sentido, afirmamos que el cooperativismo debe mantener una actitud de constante crítica frente a la empresa capitalista y aunque viva y se desarrolle dentro de la sociedad de mercado pletórico o capitalista debe mostrar su actitud de no reconciliación con el mundo que dicho mercado simboliza. La empresa cooperativa, y en general el ámbito de la Economía Social, se muestran como el símbolo de una concepción de la empresa basada en una idea de hombre sustentada en los valores de la participación y la supremacía del mismo sobre el capital que se traduce en una repartición equitativa de la riqueza y la consiguiente igualdad producida por dicha redistribución.

Nuestra sociedad, tal y como ha demostrado recientemente Thomas Piketty, sigue siendo profundamente desigualitaria porque la distribución de la riqueza no se realizada, con respecto al trabajo (ni tampoco al capital), de forma justa y en ella reside el motivo fundamental que genera las desigualdades sociales ${ }^{51}$. Es por ello que aun viviendo dentro de la sociedad de mercado y operando en ella en cuanto empresa, el horizonte de la empresa cooperativa debe seguir manteniendo

50 Confert. VARGAS, A. \& VACA, R.M.: «Responsabilidad Social Corporativa y cooperativismo: Vínculos y potencialidades», Revista CIERC-España, Revista de Economía Pública, Social y Cooperativa, n. ${ }^{\circ}$ 53, noviembre 2015, pp. 241-260. "de entrada el cooperativismo ha conseguido que sus principios y valores se hayan extendido a todo el sistema empresarial y sean consideradas como instrumentos de progreso. Ciertamente las ideas de participación en beneficios, las obras sociales en la empresa, o incluso el sometimiento empresarial a los intereses colectivos, que el cooperativismo proclamó ya en la primera mitad del siglo XIX, están hoy consideras como valores de progreso en las sociedades avanzadas». DIVAR, J.: Las cooperativas: una alternativa económica, op. cit., p. 90.

51 «[... en cualquier sociedad la desigualdad en los ingresos resulta de la suma de estos dos componentes: por una parte, la desigualdad en los ingresos de trabajo y, por otra, la desigualdad en los ingresos de capital. Cuanto más desigualmente están distribuidos estos componentes, mayor es la desigualdad total. En abstracto, sería muy posible imaginar sociedades en las que la desigualdad con respecto al trabajo fuera muy elevada mientras que la existente respecto al capital fuera mucho menor; otras sociedades en las que sucediera lo inverso, $y$, por último, sociedades en las que los dos componentes fueran muy desiguales o, por el contrario, muy igualitarios». PIKETTY, T.; El capital en el siglo XXI, F.C.E., México, 2014, p. 266 
como ideal regulativo de su actividad, como meta utópica pero en un sentido proyectivo y no meramente quimérico, la no reconciliación con dicha sociedad de mercado en la que los hombres figuran como antagonistas de un impersonal proceso productivo y no como verdaderos actores principales del progreso económico y social pues en el límite, tal y como reconoce Mario Bunge, «el único orden social que promete la realización efectiva de la democracia integral y los derechos humanos es el cooperativista» 52 .

\section{Bilbiografía}

Atienza, F.J. \& SÁnchez CocA, B., "Alcázar de San Juan: cooperativismo 1900-1950», Patronato Municipal de Cultura, Alcázar de San Juan, 2005.

AZURMENDI, J., El hombre cooperativo: pensamiento de Arizmendiarrieta, Ed. Azatza, San Sebastián, 1992.

Ballestero, E.: Economía social y empresas cooperativas, Ed. Alianza, Madrid, 1990.

Boltanski, L. \& ChiApello, E., El nuevo espíritu del capitalismo, Ed. Akal, Madrid, 2002.

Bueno, G. ¿Qué es la filosofía? Ed. Pentalfa Oviedo, 1996.

BUENO, G. "El cierre categorial aplicado a las ciencias físico-químicas», recogido en VV.AA., Actas del primer Congreso de Teoría y Metodología de las Ciencias, Ed. Pentalfa, Oviedo, 1982.

Bueno, G. El papel de la filosofía en el conjunto del saber, Ed. Ciencia Nueva, Barcelona, 1972.

Bueno, G. Teoría del Cierre Categorial. Vol. 1, Ed. Pentalfa, Oviedo, 1992.

Bueno, G., "Sobre la idea de dialéctica y sus figuras», El Basilisco, n. 19, Oviedo, 1995.

BunGE, M., Filosofía y Sociedad, Ed. Siglo XXI, Buenos Aires, 2008.

CALDERÓn MILÁN, B \& CALDERón MiLÁN, M.J., "Cómo afrontan la crisis las COOperativas en España: comparativa de trayectorias laborales a partir de la Muestra Continua de Vidas Laborales», Rev. CIRIEC España de Economía Social, Pública y Cooperativa, n. 76, Diciembre 2012.

Chalmeau R. \& Gallo A. "La coopération chez les primates», L'année psychologique. Vol. 95, 1995.

Cotarelo García, R., «Los precursores de la Teoría socialista: Saint-Simon, Charles Fourier, Robert Owen», en TezAnOS, J.F., Teoría política del socialismo, Ed. Sistema, Madrid, 1993.

DIVAR, J., Las cooperativas: una alternativa económica, Ed. Dykinson, Madrid. ENGELS, F., «La situación de la clase obrera en Inglaterra», Ed Progreso, Moscú, 1979.

52 BUNGE, M.: Filosofía y Sociedad, Ed. Siglo XXI, Buenos Aires, 2008, p. 124. 
Fletcher, J.A. \& Doebel, M. «A simple and general explanation of altruism», Proc. R. Soc. B. 276, 2009.

Friedman, M., "The Social Responsibility of Business is to Increase its Profits», The New York Times Magazine, 1970.

Fuentes Ortega, J.B. "La teoría del origen trófico del conocimiento de Ramón Turró: Un ensayo sobre su trasfondo histórico-filosófico y sus posibilidades de desarrollo teórico en el sentido de una concepción (neo) aristotélica de la vida». Rev. Psychologia Latina, Vol. 1, 2010.

GADEA Soler, E., «Estudio sobre el concepto de cooperativa: Referencia a los principios cooperativos y su discutida vigencia», JADO: boletín de la Academia Vasca de Derecho, n. ${ }^{\circ}$ 17, año 7, 2009.

García González, J., 25 años forjando sueños, Ed. Gredos San Diego Cooperativa, Madrid, 2010

Gómez PortILLo, I., La evolución de la cooperación y el origen de la sociedad humana (Tesis Doctoral) Dep. de Físicas, Grupo de Física Estadística, de la Universidad Autónoma de Barcelona, 2013.

Hegel, G.W.F., Ciencia de la lógica, Tomo II, Ed. Solar/Hachette, Buenos Aires, 1968.

Heredia Doval, D. Redes, sistemas y evolución: hacia una nueva biología (Tesis Doctoral), Dep. de Biología Evolutiva y Biodiversidad, Facultad de Ciencias, Universidad Autónoma de Madrid, 2013.

KropotKIN, P. El apoyo mutuo, Ed. Madretierra, Colombia, 1989.

LAMBERT, P., La doctrina cooperativa, Ed. Intercoop, Buenos Aires, 1970.

LINARES GARRIGA, J.E., «El aprendizaje cooperativo: aprender a cooperar, cooperando», recogido en Gómez PORTILLO, A. (coord.), Habilidades sociales para la mejora de la convivencia en los centros, Ed. Consejería de Educación y Cultura, Murcia, 2006.

Marcuello, C. \& NAChar-CALDerón, P.: «Sociedad cooperativa y socio cooperativo: propuesta de sus funciones objetivo», Documentos de trabajo (Universidad de Zaragoza, Facultad de Economía y empresa), n. ${ }^{\circ} 2,2012$.

MARX, K., «Crítica del Programa de Gotha», Obras Escogidas en 3 vol. (Vol. III), Ed. Progreso, Moscú, 1977.

MARX, K., «Trabajo asalariado y capital», Obras Escogidas en 3 vol. (Vol. I) Ed. Progreso, Moscú, 1977.

MarX, K., El Capital, Tomo III, F.C.E., México, 1968.

McCAIN, R.A., "Cooperative games and cooperative organizations», The Journal Socio-Economics, 37, 2008.

Merino HeRnÁndez, M.: «Los orígenes del cooperativismo moderno y el socialismo premarxista», GEZKI Revista vasca de Economía Social, N. ${ }^{\circ}$ 1, 2005.

MonsalVE, S., El programa Nash: ¿es mejor cooperación que competencia? en «John Nash y la teoría de juegos», Lecturas matemáticas, Vol. 24, 2003.

Monzón CAMPOS, J.L., «Las cooperativas de trabajo asociado ante la reforma de los principios cooperativos», REVESCO, Revista de estudios cooperativos, n. ${ }^{\circ} 61,1995$.

Morgenstern, O. \& Neumann, J., Theory of games an economic behavior, Princeton University Press, Princeton, 1953. 
Morgenstern, O., «La teoría de los juegos y del comportamiento económico», American Economic Review, Yale University,Tomo XXXVIII, 1948.

Navarro, A. Contra natura. La esencia conflictiva del mundo vivo. Servicio de Publicaciones de la Universidad de Valencia, 2009.

Pérez Navarro, J., Teoría de juegos (Prólogo), Ed. Pearson Educación, Madrid, 2004.

PiAget, J., El comportamiento motor de la evolución, Ed. Nueva Visión, Buenos Aires, 1986.

PiAget, J., Psicología y pedagogía, Ed. Ariel, Barcelona, 1969.

PIKETTY, T., El capital en el siglo XXI, F.C.E., México, 2014.

QuiJano, J.E., Historia y doctrina de la cooperación, Ed. Universidad Cooperativa de Colombia, Bogotá, 2004.

QuintANILA, M.A. (COORD), Diccionario de Filosofía Contemporánea, Ed. Sígueme, Salamanca, 1976.

Reventós, J.: El movimiento cooperativo en España, Ed. Ariel, Barcelona, 1960.

Rodríguez Duplá, L.: «Las ideas biológicas de Max Scheler», $\Delta \alpha \iota \mu \omega v$. Revista Internacional de Filosofía, n. ${ }^{\circ}$ 57, 2012.

ROUSSEAU, J.J., El contrato social, UNAM, México, 1984.

SABATER Pl, J. El chimpancé y los orígenes de la cultura, Ed. Anthropos, Barcelona, 1984.

SaINT Simon, H., El nuevo cristianismo, Ed. Biblos, Buenos Aires, 2004.

UGARTE AzPIRI, L.M., "Mondragón Corporación Cooperativa «Historia de una experiencia», Revista de Estudios de Juventud, n. 51, 2001.

VARGAS, A. \& VACA, R.M., "Responsabilidad Social Corporativa y cooperativismo: Vínculos y potencialidades», Revista CIERC-España, Revista de Economía Pública, Social y Cooperativa, n. ${ }^{\circ}$ 53, noviembre 2015. 